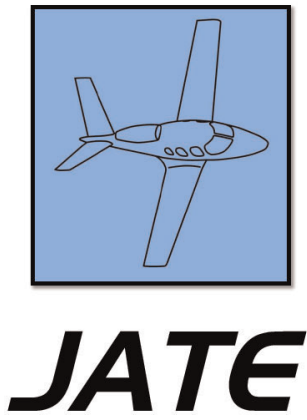

Journal of Aviation Technology and Engineering 6:2 (2017) 2-25

\title{
Modeling and Computation of the Maximum Braking Energy Speed for Transport Category Airplanes
}

\author{
Nihad E. Daidzic \\ (AAR Aerospace Consulting, LLC)
}

\begin{abstract}
Transport-category or FAR/CS 25 certified airplanes may occasionally become braking energy capacity limited. Such limitation may exist when heavy airplanes are departing airports at high-density altitudes, on relatively long runways, and/or possibly with some tailwind component. A maximum braking energy $V_{M B E}$ speed exists which may limit the maximum allowable takeoff decision/action speed $V_{l}$. The ever-existing possibility of high-speed rejected takeoff in such conditions may also limit the airplane gross weight for declared available distances. To gain deeper insights and acquire better understanding of the topic, a theoretical model of the maximum braking energy and the related $V_{M B E}$ speed for T-category airplanes was developed. The total kinetic energy of an airplane includes translational and rotary kinetic energy and the potential height-energy component for sloped runways. Time-dependent airplanes' mechanical power expression has been derived. Weight transfer during dynamic braking has been implemented in the full nonlinear model. Added mass due to rotary inertia of spinning components has been incorporated and assumed constant. The brakes thermal model is based on a lumpedparameter analysis of ventilated brake rotors and stators; the thermal model is based on a small Biot-number approximation and sufficiently well describes the physics of friction braking. The nonlinear differential equations of motion and the differential thermal model are coupled. A nonlinear model incorporating a set of ordinary differential equations with tire slip can be solved numerically. This model enables determination of the entire history of translational and angular accelerations and speeds, longitudinal distance, forces, torque, and disc temperature during braking. A simpler model assuming constant physical and thermodynamic parameters is solved analytically for constant negative acceleration. This linear analytical model has been used as a workhorse method in our calculations. A new semiempirical expression of temperature-dependent friction coefficient on brake rotor-stator pairs has been proposed. A theoretical model of maximum braking energy speed $V_{M B E}$, which includes density-altitude, runway slope, and wind effects as parameters, has been developed for the first time to the best of our knowledge. A comparison of the theoretical $V_{M B E}$ model showed good agreement with measured and approved data for the B737-400 airplane at different density altitudes with and without, individual and combined, runway slope and tailwind effects. Results for new and fully worn brakes were obtained showing the effect of elevated temperatures on brake fade and consequently braking time and distance.
\end{abstract}

Keywords: transport-category aircraft, rejected takeoffs, maximum brake energy, maximum brake energy speed, tire dynamics, thermal model of disc brakes, heat transfer, brake fade, tribology 


\section{Introduction}

Friction braking systems are essential safety features in transport-category (T-category) FAR/CS 25 certified airplanes (Daidzic, 2016c; EASA, 2007; FAA, 2014). Typically, a modern T-category airplane will have a main landing gear bogie (FAA, 2012b; Jeppesen, 2007a; Moir and Seabridge, 2008; Neese, 1991) with multiwheel design incorporating two, four, or six wheels (tandem configuration). Some jumbo airplanes, such as B747, A340, and A380, also have one or more body gears for structural reasons, i.e., to distribute aircraft weight more evenly, and also because of the need for more braked wheels. Originally Soviet Union-made, and still the largest aircraft in the world, weighing 640 metric tons $(1,411,200 \mathrm{lbf})$, the Antonov An-225 Mriya (which was designed to ferry the Buran space shuttle orbiter) has seven axles and 14 wheels/tires per body landing gear bogie. Modern T-category airplanes usually have steerable nose-gear (NG) and two, or more, main-gears (MG) arranged in a tricycle layout. Typically, only MGs are equipped with brakes (Jeppesen, 2007a; Moir and Seabridge, 2008), although B727 also had NG brakes (Neese, 1991). Left and right airplane brakes (pedals) work independently. On the other hand, MGs typically have no steering capability (except, for example, A380). Aircraft brakes can be classified as service brakes, emergency (alternate) brakes, and parking brakes.

High-speed rejected takeoffs (RTOs), quick turnaround flights, and heavy and/or abnormal (e.g., zero-flap) landings may exceed the maximum brake energy (MBE) absorbing capability of disc (or disk) brakes resulting in runway overrun. Taxiing airplanes may require frequent use of brakes, although a good standard operating practice (SOP) is to minimize their use. High takeoff weight (TOW) and high density altitude (DA) takeoffs on long runways with tailwind (TW) resulting in high rolling groundspeeds (GS) are the prime suspects for exceeding MBE limitations. Additionally, improved- $V_{2}$ or overspeed-takeoffs designed to increase climb-limited TOW (CLTOW) may have $V_{1}$-speeds limited by MBE capacity (Daidzic, 2014).

Airplane brakes are critical to flight safety. Brake malfunctions could lead to runway overruns and veeroffs during landings (normal and abnormal) and RTOs. Airplanes have some unique braking requirements and limitations that road and rail vehicles do not have. A Maximum Quick Turnaround Weight (MQTW) limit exists for high-frequency short-haul operations. Certified fuse-plug-no-melt energy defines MQTW. If landing is executed at a weight exceeding MQTW, a mandatory waiting period before next takeoff is compulsory. Repeated and frequent landings and taxiing accumulates thermal energy in brakes, which is slow to dissipate. Every subsequent landing and taxiing decreases remaining breaking energy capacity. Complicated taxi routes at congested airports with many intermediate stops heat up brakes, substantially reducing available braking energy for possible RTO. According to FAR 25.733(e), large T-category airplane tires are required to be inflated mostly with Nitrogen $\left(\mathrm{N}_{2}\right)$ with no more than $5 \%$ of Oxygen $\left(\mathrm{O}_{2}\right)$ by volume (FAA, 2014), primarily to prevent combustion reaction. FAR/CS 25 requires wheel and tire protection from over-temperature condition. Wheel fuse plugs are installed to melt and release tire pressure (deflate) if the braking energy/heat input exceeds the specified maximum. Takeoff accelerate-stop (AS) MBE limitation is typically the most critical in terms of energy requirements and is expressed through the maximum braking energy $\left(V_{M B E}\right)$ $\mathrm{V}$-speed limit. Takeoff decision-action speed $V_{1}$ (in IAS, CAS, or EAS) can never exceed $V_{M B E}$ (also in IAS, CAS, or EAS for existing conditions) so that in the case of highspeed RTO there will be sufficient braking capacity to absorb and dissipate into heat all existing mechanical energy of motion within the short time period available. In extreme cases TOW must be reduced to accommodate for the MBE limit. Simply adhering to $V_{M B E}$ speed limit by no means implies that required accelerate-stop distances (ASDR) will be met (Daidzic, 2016b). MBE RTOs will certainly lead to fuse plugs melting and tires deflating (Chapman, Kornstaedt, \& Lignee, 2014). The reason that tire temperatures continue increasing for many minutes after the high-energy stops is due to heat soaking. It takes a finite amount of time for mostly conduction heat transfer to distribute all that thermal energy absorbed by brakes. Insulation only slows down heat transport but cannot stop it.

One high-speed RTO accident was directly attributed to exceeding MBE capacity and brake failure. A McDonnell Douglas DC-10-30, registered as N136AA, departing Dallas/ Fort Worth International Airport, TX (KDFW) as an American Airlines Flight 70 on May 21, 1988, destined for Frankfurt (Germany), performed a high-speed RTO due to takeoff warning horn (apparently due to slats disagreement, which was later found to be erroneous). The brakes failed (faded) once the airplane slowed down to 130 knots (from maximum reached 178 knots GS) and exited the runway at about 97 knots, stopping about 1,000 ft beyond the runway threshold. The airplane was damaged beyond repair, with a few serious and minor injuries to passengers and crew. For more information on this and other high-speed RTO accidents, consult NTSB (1990) and FAA (1994).

Modern airplane braking systems have complex designs incorporating electronic control for optimal performance, auto-brake systems (ABS), and many protections including anti-lock (anti-skid) and touchdown protection. Small braking torques are applied automatically to stop wheel/tire rotation upon liftoff and retraction. Unlike automotive and small-airplane brakes having ventilated discs with calipers (fixed, floating, sliding) containing friction lining/pads, large T-category airplanes utilize several alternating rotors and stators that are pressed against each other to obtain breaking torque. Such brakes are called multiple-disc or more modern segmented-rotor brakes (FAA, 2012b; Neese, 1991). 


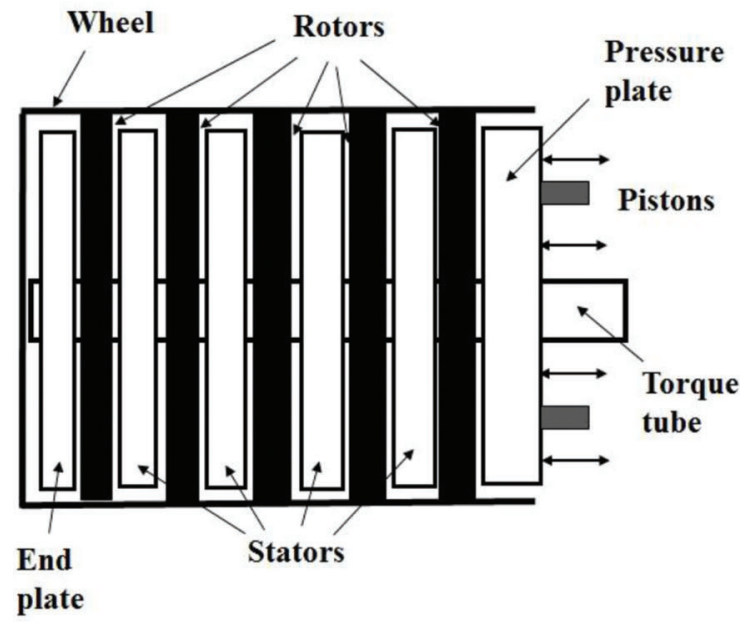

a) Rotors freewheeling. Brakes-off.

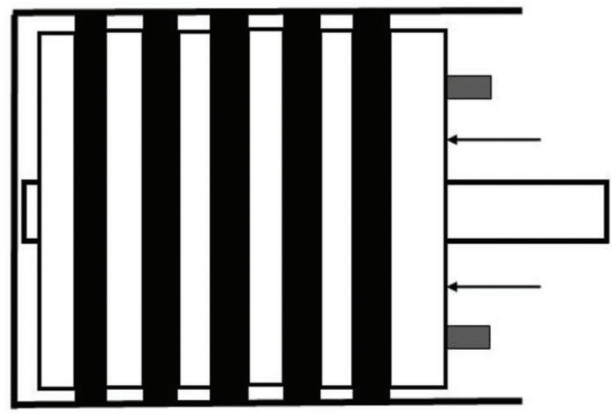

b) Rotors-Stators clamped together. Brakes-on.

Figure 1. Schematic drawing of a modern T-category airplane multiple-disc wheel brakes.

Significant progress has been made with the implementation of new carbon fiber composites for friction materials/linings. Modern carbon brakes are made of carbon-reinforced carbon (CFC). They are lighter and exhibit excellent behavior at high temperatures and last longer than steel brakes. However, they are expensive and the break wear is higher than for grey cast iron/stainless steel brakes at low temperatures.

Modern braking rotors/stators (heat pack or heat stack) are also made, in part, of carbon-fiber composites. The new fiber-reinforced ceramic (inorganic non-metallic materials) discs $(\mathrm{C} / \mathrm{SiC})$ consist of carbon fibers, carbon powder, and Silicon-Carbide resin molded under high pressure (Breuer $\&$ Bill, 2008). The new ceramic $\mathrm{C} / \mathrm{SiC}$ materials have a density of about $2,300 \mathrm{~kg} / \mathrm{m}^{3}$ (about three times lower than that of grey cast iron/steel), and exhibit very low thermal expansion of approximately $10^{-6} \mathrm{~K}^{-1}$, low thermal shock resistance, and high oxidation resistance. The main problem with steel/cast iron brakes is corrodibility and weight (Breuer \& Bill, 2008). Steel brakes wear significantly at high temperatures.

Taxiing techniques differ for steel- and carbon-brake equipped aircraft (Allen, Miller, \& Preston, 2009). Carbon brakes operate well at higher temperatures and do not "weld" (stick) as steel-brakes could at high temperatures. However, carbon brakes exhibit substandard performance during taxiing, which often requires frequent small brake applications for accurate speed control. Carbon brakes show higher wear than traditional steel-disc brakes at slow taxiing speeds. Studies and operating experience have shown that wear of carbon brakes is highest at relatively low operating temperatures $\left(100-300{ }^{\circ} \mathrm{C}\right)$. Wear of carbon brakes is roughly proportional to the number of applications. Hence, and unlike steel brakes, carbon brakes require less frequent, but more firm, brake applications to control speed (Allen et al., 2009). Similar recommendations apply to A320 and other Airbus models, both carbon-brakes equipped airplanes (Airbus, 2001). Wheel brake fans are often implemented to accelerate brake cooling. During gate stops, portable brake cooling fans can be used for quick turnaround flights. Airbus suggests using brake fans during taxiing that must be switched-off for takeoffs.

A simple drawing of modern T-category airplane multipledisc (segmented-rotor) brakes is illustrated in Figure 1. Modern brake assembly chief components are rotors (discs), stators (friction lining), hydraulic pistons, housing, an end plate, and a pressure plate. A heat stack is formed from an alternating order of rotor and stator pairs. For example, on Gulfstream Aerospace G450 the MG carbon brakes have three rotating discs (rotors), two stationary discs (stators), an end plate (stator), and a pressure plate (stator). A brake wear indicator is installed on each wheel. The stators are attached to a torque tube, which is fixed and does not rotate. The rotors are spinning between the brake stators and end/ pressure plates and are attached to the wheel. Five hydraulic actuating pistons are built in the brake housing, providing for uniform and even contact between the rotors and the stators. When the brakes are activated, hydraulic pressure increases, pushing pistons out and compressing the pressure plate against the end plate. This reduces the space between and ultimately leads to rotors and stators being pressed against each other, producing friction torque that decelerates the rotating wheel. G450 has four braked wheels in a twin configuration, and the demonstrated MBE total capacity per G450 aircraft flight manual (AFM) is 115 million ft-lbf or $156 \mathrm{MJ}$ (39 MJ/brake). In the case of MBE stop with initially cool brakes, the heat-pack representative temperature could reach $950{ }^{\circ} \mathrm{C}$.

The primary goal of this article is to present simple, reliable, and practical theory of MBE-limiting speed $\left(V_{M B E}\right)$ prediction for T-category airplanes. The entire friction braking problem and the interaction between aircraft, brakes, landing gear, and surface is extremely complex. Hence, few assumptions were made to make the theory tractable and simple enough for practical use. A $V_{M B E}$ theory developed 
includes major effects of DA, wind, runway slope, rotary inertia, and mass (weight). Additionally, a simple nonlinear lumped-parameter thermal model of airplane brakes was developed, connecting their thermal loading to airplane speed. A linear version of the full nonlinear model enables an analytical solution that can address many operational scenarios. The thermal model can be used to estimate heat loads under various conditions, such as taxiing with repeated brake applications, high-weight and/or high-speed landings, RTO's, short turnaround times, etc. Any brake frictioncouple heat-stack material could be simulated for which physical and thermal properties are known. Reference was made to relevant aviation regulations.

\section{Literature Review}

It is somewhat surprising that little to no research is being published on airplane braking systems, dynamics/physics, and operational limitations. To the best knowledge of this author, no publically available archived material exists on the direct problem of $V_{M B E}$ determination and the related theoretical braking energy considerations. Engineering and pilot-oriented books and publications provide very little insight into MBE and related issues. That is no surprise, as one has to simultaneously tackle problems of ground-effect aerodynamics, thermodynamics, heat transfer, and tribology. Ample published material on design of automotive braking systems exists, which was somewhat useful.

Tire physics/dynamics and friction models are presented in several references, such as Agrawal (1986); Canudasde-Wit, Tsiotras, Velenis, Basset, and Gissinger (2003); Dixon (1996); Gillespie (1992); Haney (2003); Jazar (2008); Medzorian (1992); Milliken and Milliken (1995); Olson, Shaw, and Stépán (2003); Pacejka and Sharp (1991); and Yager, Stubbs, and Davis (1990). References used for T-category airplane hydraulic systems, landing gears, wheels, axles, disc brakes, and anti-skid systems are from Davies (2003), FAA (2012b), Jeppesen (2007a), Lombardo (1993), Moir and Seabridge (2008), Neese (1991), and Wild (2008). A description and model of modern T-category airplane braking systems is presented in Tarter (1991). An entire special edition of collected papers titled "Emerging Technologies in Aircraft Landing Gear" (eds. J. A. Tanner, P. C. Ulrich, J. P. Medzorian, and D. L. Morris) and published by the Society of Automotive Engineers International as SAE PT-66 (Progress in Technology) is devoted to issues involving aircraft tires, brakes, and landing gears.

The MBE speed or $V_{M B E}$ is referenced and defined in many regulatory and pilot-oriented materials (Airbus, 2002; EASA, 2007; FAA, 2012a, 2014; Jeppesen, 2007b; Padilla, 1996; Swatton, 2008). All airplane performance programs and calculators will need $V_{M B E}$ input to determine maximum allowed $V_{1}$ speeds (Airbus, 2002; CAA, 2006; Daidzic, 2016b; de Lemos Viana, 2011). Daidzic (2016a, 2016b), Daidzic and Shrestha (2008), Durbin and Perkins (1962), Eshelby (2000), Padilla (1996), and Filippone (2008, 2012) were consulted for airplane takeoff and landing performance calculations. From a test- and line-pilot perspective, Davies (1971) discusses hot tire and brake temperatures issues in the case of high-GS RTOs. In such RTO cases brake temperatures can easily exceed $900{ }^{\circ} \mathrm{C}$. The author's emphasis was on the initial certification of B747-100 for British CAA. Wagenmakers (1991) points out that tire failures have been the major factor in many takeoff incidents and accidents, which caused drastically reduced stopping distances. The author also concludes that modern anti-skid and braking ABS systems with the RTO capability are significant safety features minimizing tire blowouts and stopping distances. General theory of macro-scale heat transfer is provided in many classic books of which we have specifically used: Carslaw and Jaeger (1959), Holman (1986), Myers (1987), Özişik (1985, 1989), and Welty, Wicks, Wilson, and Rorrer (2001). A recent mathematical analysis of heat conduction using Green's functions for automotive disc brakes was conducted by Talati and Jalalifar (2009).

The earliest reference that we found on airplane stopping distance with the consideration of the available and usable braking torques was provided by Saelman (1954). The earliest airplane braking energy considerations and calculations that we found were presented by Creech (1968). In his report, Creech describes a standardized method for analyzing and calculating aircraft brake energy requirements. These methods have been used in analysis of many of the USAF military airplanes, such as C-5A and F-111. Also Durbin and Perkins (1962) provide some scant information on the maximum possible and available braking torques. Agrawal (1986) gives a detailed and lengthy review and discussion of aviation tires and braking performance. Germain (2000) highlights the history of A340 development, design, testing, and certification with a section devoted to its landing gear, wheels, and brakes. Useful reference on airplane brakes and braking systems in general is found in Breuer and Bill (2008). An entire chapter was devoted to aircraft brakes, but it was mostly informal and no calculations were presented. Designs of brakes and associated systems, mostly in the automotive industry, are provided by Limpert (2011). The author provides theoretical background and discusses thermal analysis and design of disc brakes. Reif (2014) provides an overview of automotive braking systems produced by German Bosch. Khapane (2008) in his doctoral thesis gives detailed account on the landing gear dynamics and brake-gear interactions. Some useful operational characteristics of carbon brakes and MBE testing come from Allen et al. (2009), Arampatzis (2013), and Chapman et al. (2014). Daidzic (2016c) has recently addressed some important facts and issues regarding aircraft brakes as a part of installed stopping systems in T-category airplanes. 


\section{Methods and Materials}

The old FAR 25.735 (Amendment 25-92 from 1998) introduced various new design criteria for T-category airplane brakes approval. Different sections of FAR 25 address landing and RTO kinetic energy capacity and requirements for brakes. Essentially, qualification testing using fully worn brakes of its allowable wear range is required. The brake kinetic energy requirement must be based on a rational analysis of the sequence of events expected during RTO. Alternatively, the old FAR 25.735(h)(2) allows the kinetic braking energy requirement for each braked main wheel to be derived using the following relationship (FAA, 2000):

$$
K E=\frac{0.0443 \times W \times v^{2}}{N}
$$

Here, $K E$ is kinetic energy per braked wheel in ft-lbf, $N$ is the number of braked main wheels, $W$ is airplane weight in lbf at which kinetic energy absorption is being evaluated, and $V$ is speed in knots. Speed $V$ must be larger than the $V_{S O}$ speed for the case when landing kinetic energy is being evaluated. For example, a 150,000 lbf (68 metric ton) B737-400 at 170 knots GS with four braked wheels will require brake absorption capacity of about 48 million $\mathrm{ft}-\mathrm{lbf}$ per each wheel/brake or $1.92 \times 10^{8} \mathrm{ft}-\mathrm{lbf}$ total (192 million ft-lbf).

The FAR 25.101(i) requires that AS and landing distances, prescribed in sections 25.109 and 25.125 respectively, must be determined with all the airplane wheel brake assemblies at the fully worn limit of their allowable wear range (FAA, 2014). The latest FAR 25.735(f)(1), (2), and (3) (FAA 2014) address kinetic energy requirements for (1) design landing stop, (2) maximum kinetic energy accelerate-stop, and (3) most severe landing stop. According to the latest FAR 25.735 version, the maximum kinetic energy AS maneuver is an RTO for the most critical combination of airplane takeoff speed and weight. The AS RTO brake kinetic energy absorption requirement of each wheel, brake, and tire assembly must be determined. It must be also substantiated by dynamometer testing that the wheel, brake, and tire assembly is capable of absorbing at least this level of kinetic energy throughout the defined wear range of the brake (FAA, 2014). Dynamometer tests are conducted with $100 \%$ worn brakes for new production airplanes. The energy absorption rate derived from the airplane manufacturer's braking requirements must be achieved. The mean deceleration must not be less than $6 \mathrm{ft} / \mathrm{s}^{2}\left(1.8 \mathrm{~m} / \mathrm{s}^{2}\right)$. The EASA certification standard requirements CS 25 (EASA, 2007) are often equivalent to the FAA's requirements. FAA's latest Advisory Circular AC 25-7C (FAA, 2012a) specifies many details of how testing of brakes and compliance with the latest FAR 25 rules is to be achieved. FAA's AC 25-22 (FAA, 2000) provides methods acceptable to the administrator (FAA) for showing compliance with the type certification requirements for transport airplane mechanical systems and equipment installations (including brakes, wheels, and tires). The maximum energy RTO demonstration should be preceded by at least a threemile taxi, with at least three intermediate full stops, using normal braking and with all engines operating (FAA, 2012a). Specifically, FAR 25.109(i) requires that no more than $10 \%$ of allowable wear range remains on each braked wheel (FAA, 2014). On the other hand, Amendment 25-92 to which many new airplanes were certified required fully worn brakes in determining braking energy capacity. The AC $25-7 \mathrm{C}$ uses $90 \%$ or more worn brakes (Chapman et al., 2014) of its allowable range (not more than $10 \%$ of useful range remaining) simply for flight demonstration logistics and testing safety (for example, to prevent tire blowouts during flight tests). Calculations are subsequently made to reduce test data to fully worn brakes condition (FAA, 2012a). Flight testing of high-energy stops are usually done in the last phase of certification tests as there is a high risk of equipment loss due to uncontained wheel and tire fires and even serious injury to the flight and fire crew. After MBE RTO test, the brakes and wheels are written off. The fire crew is not supposed to intervene for at least 5 minutes, as that would invalidate the test (Chapman et al., 2014). FAR 25.735 has been more recently revised by Amendment 25-107, which moved the RTO kinetic energy rating requirements into FAR 25.735(f) (FAA, 2012a). An interested reader should consult AC 25-7C for details on brake testing and flight demonstrations.

\section{Mathematical Model of Friction Braking}

A mathematical model of braking action of FAR/CS 25 certified T-category airplanes is now presented. A rigidairplane braking model including the rotary inertia of wheels, discs, tires, and axles is developed. The runway is assumed smooth with a small positive or negative average incline to simulate uphill or downhill takeoffs and landings. Newtonian laws of classical mechanics in a topocentric, non-rotating, flatearth quasi-inertial frame-of-reference are assumed for short braking action durations and distances. The conservation of the linear momentum of constant-mass motion (along the $x$-axis) and the conservation of angular momentum about the wheel/tire center delivers two balance equations in the substantially inertial frame-of-reference, yielding:

$$
\begin{aligned}
M_{A} \cdot \frac{d v}{d t}= & \sum_{i} F_{i}=-F_{B}-F_{D}-F_{\text {roll }}-M_{A} \cdot g \cdot \sin \phi+F_{\text {res }} \\
I_{R} \cdot \frac{d \omega}{d t}= & \sum_{i} \tau_{i}=F_{B} \cdot R_{d y n}-\tau_{B}-\tau_{f} \\
& \frac{d v}{d t}<0 \quad \text { and } \quad \dot{\omega}<0 \quad \text { when braking }
\end{aligned}
$$

Here, $v$ is the longitudinal (GS) speed component of the aircraft's CG, $\omega$ is the tire/wheel angular speed, $M_{A}$ is 
the airplane mass, $R_{d y n}$ is the tire dynamic braking radius, $F_{B}$ is the longitudinal friction (adhesion) braking force, $F_{D}$ is aerodynamic drag in ground effect (TAS dependent), $F_{\text {roll }}$ is the rolling friction on $\mathrm{NG}$ and MGs, $F_{\text {res }}$ is the residual thrust force, $\tau_{B}$ is the breaking torque produced by disc brakes per wheel/tire, and $\tau_{f}$ is the parasitic axles/ bearings' friction torque. Other minor forces and torques are neglected in MBE analysis.

For small runway slopes, we assumed $\sin \phi \approx \phi$ and $\cos \phi \approx 1$ The translational speed and acceleration are presented in regard to CG (Center-of-Gravity). Negative inclination or negative effective runway gradient (downhill, downslope) implies accelerating force. Residual force is due to idle (flight/ground) thrust. Equations (2) can be transformed into the conservation of the total energy incorporating translational and rotational kinetic and the potential height energy as:

$$
\begin{aligned}
\frac{d}{d t}\left(\frac{1}{2} M_{A} k v^{2}-M_{A} g \phi|x|\right) & =-F_{B} \cdot v \cdot(1-s)-F_{B} \cdot v \cdot s \\
- & F_{D} \cdot v-\left(\tau_{f} \cdot \omega+F_{\text {roll }} \cdot v\right)+F_{\text {res }} \cdot v
\end{aligned}
$$

The added-mass coefficient $\mathrm{k}$ is due to rotary inertia of tires, wheels, brake discs, and axles:

$$
k(s)=1+\frac{I_{R} \cdot(1-s)^{2}}{M_{A} \cdot R_{w}^{2}}
$$

Here, $R_{w}$ is a free-rolling tire radius. The kinetic energy balance can be also expressed in the energy-work conservation form directly from Equation (2), stating that the change in translational kinetic energy is due to the work $\Psi$ of conservative and non-conservative forces along the path:

$$
\begin{gathered}
\frac{d}{d x}\left(\frac{M_{A} \cdot v^{2}}{2}\right)=-F_{B}-F_{D}-F_{r o l l}-M_{A} g \phi+F_{r e s} \\
\Psi=\int \vec{F} \cdot d \vec{L}
\end{gathered}
$$

The total moment of inertia $I_{R}$ of rotating parts is calculated from the rotary inertia of all landing gears' rotating components (Davies, 2003; Spiegel \& Liu, 1999). The tire longitudinal slip in braking can be defined as (Dixon, 1996; Gillespie, 1992; Olson et al., 2003):

$$
\begin{gathered}
s=\frac{v-R_{d y n} \omega}{v}=1-\frac{v_{w}}{v} \quad 0 \leq s \leq 1 \quad 0 \leq v_{w} \leq v \\
R_{d y n}<R_{w}
\end{gathered}
$$

The longitudinal slip is a result of tire (tread) elastic deformation during braking and the reduced tire circumference, which is expressed through dynamic or effective tire radius that is also very difficult to measure (Canudasde-Wit et al., 2003). During braking the effective wheel speed $v_{w}$ is less than the aircraft forward speed $v$. Although brakes are responsible for almost all of the motion energy dissipation, aerodynamic drag, tire slip, NG rolling, and parasitic friction of rotary components (axles, shafts, bearings, etc.) absorb some of the total energy. Two additional equations define average vertical acceleration and pitching moment dynamics (Nelson, 1998):

$$
\begin{gathered}
M_{A} \cdot \frac{d u}{d t}=N_{N G}+N_{M G}-W+L+L_{T}=0 \\
I_{y y} \cdot \frac{d q}{d t}=N_{N G} \cdot d_{1}-N_{M G} \cdot d_{2}-F_{B} \cdot d_{3}-L \cdot d_{4}-L_{T} \cdot d_{5}=0 \\
q=\dot{\theta}
\end{gathered}
$$

During ground roll both motions are approximately zero. Pitch stiffness and pitch damping were neglected for small ground-roll pitch changes as expressed in Equation (7). Here, $u$ is the vertical velocity component (normal to local horizontal) of the aircraft's CG, $\theta$ is airplane pitch angle, $q$ is the pitching angular speed, $M_{A}$ is the mass of the aircraft, $I_{y y}$ is airplane pitching moment of inertia, $N_{N G}$ and $N_{M G}$ are normal reaction forces on tires, $W$ is weight, $L$ is airplane lift, $L_{T}$ is tail's control force (up or down), $F_{B}$ is the longitudinal braking force due to friction (adhesion), and $d$ 's are various distances from the airplane's CG and are taken approximately constant. Forces and associated torques during ground roll are illustrated in Figure 2.

Equation (7) implies that average change in the pitching moment and the vertical acceleration vanishes defining instantaneous weight redistribution during dynamic braking. The tire-road braking force is defined using the constitutive law of friction:

$$
F_{B}=\mu(s, v) \cdot N=f(s) \cdot \mu_{p}(v) \cdot N
$$

Here, $N$ designates the normal surface reaction force. The estimation of unknown coefficients in the normalized coefficient of friction (COF) for existing tire-surface model is presented in Appendix A. It was assumed that the peak and sliding COF are roughly linearly dependent on GS. Aerodynamic drag and the residual thrust from the remaining $\left(n_{e}-1\right)$ operating engine(s) is:

$$
\begin{aligned}
& F_{D}=\frac{1}{2} \cdot \rho_{S L} \sigma v^{2} \cdot C_{D, G E} \cdot S_{r e f} \\
& F_{r e s} \approx\left(n_{e}-1\right) \cdot 0.08 \cdot \sigma \cdot T_{\max , S L}
\end{aligned}
$$

In this analysis we neglected windmilling drag of an inoperative engine. If the RTO is the result of an event other than engine failure (e.g., tire blowout), then all throttled engines will be producing some residual thrust.

\section{Weight Transfer During Dynamic Braking}

When the airplane is static on the ground most of the weight is supported by MGs. The CG of an airplane is between the NG and MGs, but quite closer to MGs. Using the 


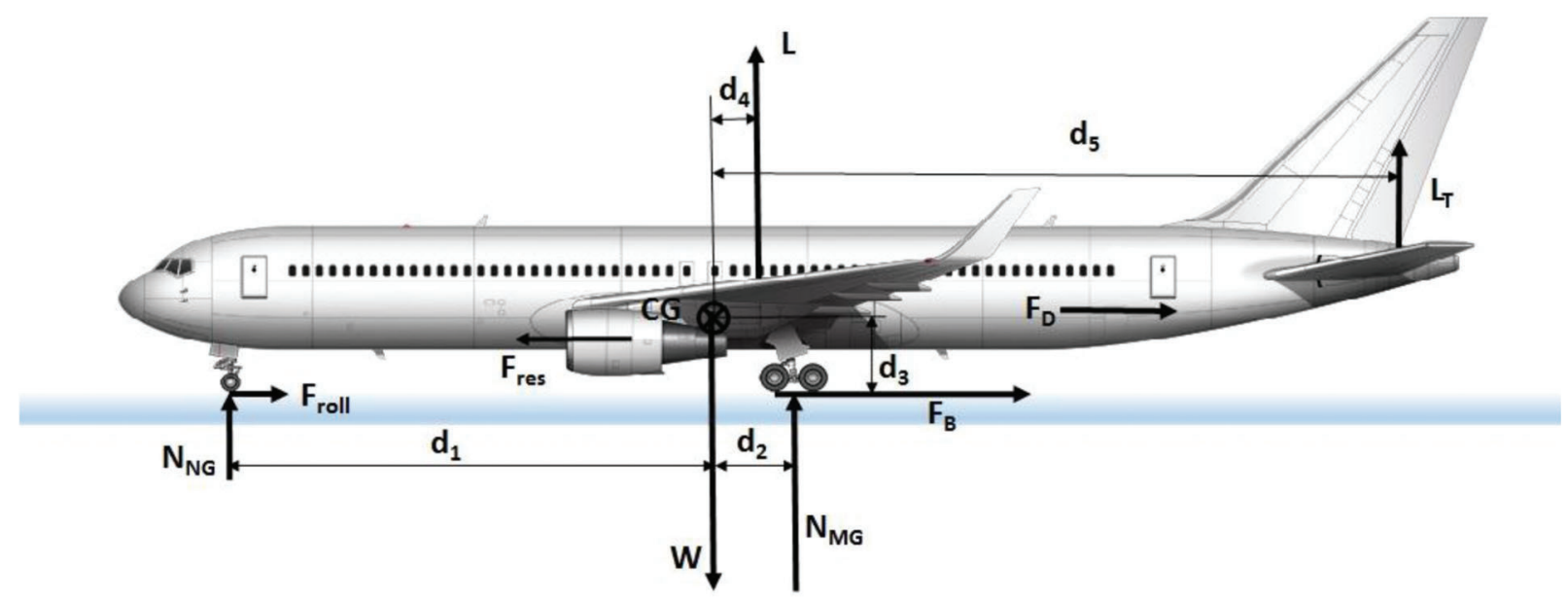

Figure 2. Forces and torques on NG and MG during static and dynamic-braking conditions. (B767-300 illustration/drawing courtesy of http://www. norebbo.com/2014/07/boeing-767-300-blank-illustration-templates/.) Not to scale.

illustration from Figure 2, the location of the CG, and the static force and momentum balance, the normal reaction on the NG and MGs can be calculated from:

$$
\begin{aligned}
& N_{N G} \cdot d_{1}-N_{M G} \cdot d_{2}=0 \quad N_{N G}+N_{M G}=W \\
& d_{1}+d_{2}=w b=\text { const. }
\end{aligned}
$$

Here, $w b$ designates a wheelbase (WB), which is constant for a specific airplane model (see also Daidzic, 2016c). CG can move between the maximum forward and aft limits. For example, B737-400 has wheelbase of 14.27 $\mathrm{m}$ or $46 \mathrm{ft}$ and 10 inches (Boeing, 2013). B767-300ER has wheelbase of $22.76 \mathrm{~m}$ (Boeing, 2005) and track of $9.3 \mathrm{~m}$. According to Equation (10), $N_{N G}=\left(d_{2} / d_{1}\right) \cdot N_{M G}$. Typically, $d_{1} \approx 10 \cdot d_{2}$, and since, $N_{M G}=\left(d_{1} / w b\right) \cdot W$, the (two) MGs support about $91 \%$, and the NG alone about $9 \%$, of the aircraft weight in static condition. During dynamic braking, the balance of forces and torques changes (see Figure 2). As active forces and torques change, so will the normal reaction forces on NG and MGs. In the case of negligible pitch inertia and damping, the instantaneous force and torque balances are:

$$
\begin{aligned}
& N_{N G} \cdot d_{1}-N_{M G} \cdot d_{2}-F_{B} \cdot d_{3}-L \cdot d_{4}-L_{T} \cdot d_{5}=0 \\
& N_{N G}+N_{M G}=W-L-L_{T}
\end{aligned}
$$

Moments from the residual thrust, aerodynamic drag, and rolling NG tire friction were neglected in above expressions due to small magnitudes and because they almost cancel each other. It is assumed that the control column is positioned to create an upward tail aerodynamic force pitching an airplane downward and unloading MGs somewhat. This action puts more load on the NG, which may additionally compress NG oleo-strut, reducing pitch and AOA and ultimately resulting in less aerodynamic lift and more load on MGs. In the case of RTO or landings, all spoilers (lift dump system) are deployed and together with the low incidence angle are reducing main-wing lift generation, putting more weight on wheels/tires. For realistic modeling, the change of airplane CG during dynamic braking should be considered.

\section{Energy Considerations During Braking}

The total energy of an aircraft in motion on a runway that has small effective gradient (average slope) is evaluated. The relevant total energy that a rolling aircraft possesses consists of three parts, i.e., translational linear, kinetic rotary, and potential (Limpert, 2011):

$$
\begin{aligned}
E_{B}= & \underbrace{\left(\frac{M_{A}}{2}\right) \cdot\left(v_{1}^{2}-v_{2}^{2}\right)}_{\text {Translational kinetic }}+\underbrace{\left(\frac{I_{R}}{2}\right) \cdot\left(\omega_{1}^{2}-\omega_{2}^{2}\right)}_{\text {Rotational kinetic }} \\
& -\underbrace{M_{A} \cdot g \cdot\left|x_{1}-x_{2}\right| \cdot \phi}_{\text {Potential }}=E_{1}-E_{2} \quad \phi \leq \geq 0
\end{aligned}
$$

Downslope implies $\phi<0$, in which case potential (height) energy is added to the total energy. Upslope will assist braking. Since full-stop implies zero final total energy (kinetic translational, kinetic rotary, and potential), we can write:

$$
\begin{gathered}
E_{B}(v, \omega, h)=\left(\frac{M_{A}}{2}\right) \cdot v^{2}+\left(\frac{I_{R}}{2}\right) \cdot \omega^{2}-M_{A} \cdot g \cdot h \\
h=|x| \cdot \phi \leq \geq 0
\end{gathered}
$$

It is usual to transform the rotary inertia into translational mass inertia using the tire/wheel assembly radius. Instantaneous total energy of airplane stopping must be equal to or smaller than MBE, resulting in:

$$
E_{B}\left(M_{A}, k, v, \phi\right)=\frac{M_{A} \cdot k}{2} \cdot v^{2}-M_{A} \cdot g \cdot x \cdot \phi \leq E_{M B E}
$$

Previously introduced coefficient of added mass $k$ accounts for all the rotary motion inertia that also needs 
to come to full stop. For example, $k$ can have values of 1.25 to 1.6 for trucks in low gear and 1.03 to 1.06 in high gear (Limpert, 2011). No such information was found for T-category airplanes. Airplane wheels/tires have no tractive capability and no transmissions and engine rotary inertia, and this factor is usually quite small (1.003 to 1.02). Rotary inertia of idling jet engines has practically no influence on the braked rotary-mass.

The total mechanical power of a moving airplane on an inclined surface, with the rotary inertia included, is obtained by differentiating total energy from Equation (14) with respect to time:

$P_{B}(t)=\left(\frac{d E_{B}}{d t}\right)=M_{A} \cdot k \cdot a_{A}(t) \cdot v_{A}(t)-M_{A} \cdot g \cdot v_{A}(t) \cdot \phi$

where instantaneous acceleration and speed are:

$$
a_{A}(t)=\frac{d v_{A}(t)}{d t} \quad v_{A}(t)=\frac{d x(t)}{d t}
$$

The energy of motion must be dissipated and transformed into heat with entropy increasing. While some energy is being dissipated directly through aerodynamic drag (formation of eddies and vortices first), rolling and sliding tire, and axle/bearings lubrication friction, most of it is being absorbed by brakes. And while many parts of the braking system will end up absorbing some of that heating power, the overwhelming part goes into heating brake heat packs. Brake rotors and stators are essentially heat sinks. Some of the braking energy and power also goes into material plastic deformations, abrasion and vaporization of friction material, heating and possibly boiling of brake fluid, etc. If tires are fully locked then all the mechanical power must be absorbed by tires, which quickly leads to their destruction, much reduced stopping capacity and the directional stability on the ground may be completely lost. For example, a wide-body T-category airplane such as B767-300ER during high-speed RTO at maximum structural TOW (MSTOW) may have to dissipate almost 700 Mega-Joules (MJ) of energy in a matter of 15-16 seconds and may need about 2,100 ft of dry runway, using 8 brakes in twin-tandem bogie wheel configuration.

The total energy and the instantaneous power will be maximum at the braking onset and will decrease to zero over length and time. As the first action is taken to stop an airplane and the brakes are first applied (FAR 25.109), the aircraft will still have some residual acceleration and the maximum speed reached before deceleration is a bit higher than $V_{M B E}$ as illustrated in Figure 3. When they fail (fuel cut), jet engines will spool down gradually and produce windmilling drag. If only throttled back, jet engines will still produce some residual thrust. More details of acceleration transition-region dynamics can be found in Daidzic (2016b).
Thus, the $V_{M B E}$ (in terms of GS) is the maximum speed from which braking to full-stop can be achieved without brakes (disc brakes) experiencing significant fade and temperatures exceeding the maximum allowed. Brake fade is a serious problem. The effect of low-to-moderate brake fade is incorporated into stopping distance calculations. The friction-couple $\mathrm{COF}$ is a function of temperature $\mu=\mu(T)$ (Appendix B). Brake fade is caused by high temperatures at the disc-lining interface and low ensuing COF (Breuer \& Bill, 2008). Thus, for a level runway we can write in terms of GS:

$$
v_{M B E} \leq \sqrt{\frac{2 \cdot E_{M B E}}{M_{A} \cdot k}}=\sqrt{\frac{2 \cdot g \cdot E_{M B E}}{W_{A} \cdot k}}
$$

It is more convenient to express $V_{M B E}$ in terms of EAS/CAS, i.e., $E A S=T A S \sqrt{\sigma}\left(\sigma=\rho / \rho_{S L}\right)$. As shown in Daidzic (2016b), the difference between CAS and EAS is practically negligible for typical takeoff airspeeds. In the case of wind speed (WS measured as TAS) aligned with the runway, accounting for wind factorization (WF) and using Equation (14), we obtain:

$$
\begin{aligned}
& v_{M B E}[E A S] \\
& \leq \sqrt{\sigma} \cdot\left[\sqrt{\frac{2 \cdot E_{M B E}}{M_{A} \cdot k}}\left(1+\frac{M_{A} g L_{B} \phi}{E_{M B E}}\right)^{1 / 2}-W F \cdot W S\right]
\end{aligned}
$$

According to FAR 25.105(d)(1), the minimum regulatory wind factor (RWF) is $+150 \%$ for WS $=$ TW and, not more than, (-)50\% for WS $=\mathrm{HW}$. Manufacturers can use stricter margins, but never exceed regulatory ones. The braking distance is designated as $L_{B}$. As expected, increased DA, TW, and downslope $(\phi<0)$ will all decrease $V_{M B E}$. However, the acceleration-transition zone complicates issues as the airplane will actually decelerate from a slightly higher speed as illustrated in Figure 3. This zone is very dynamic and requires special treatment. There is a short system dead-time after (gradual) brake pedal application, and the braking force cannot just increase instantly due to inertia of components.

All significant parameters for estimation of $V_{M B E}$ are included in Equation (18), such as TW, air density (DA), runway slope, MBE capacity, and aircraft weight, including added mass due to rotary inertia. Low flap setting typically implies higher rotation and takeoff safety speeds. That may also imply high $V_{1}$ speeds and be thus limited by $V_{M B E}$. Negative runway slope and/or TW will reduce $V_{M B E}$, possibly restricting performance-limited TOW (PLTOW). The existence of unbalanced fields (UBFL) with clearways may be beneficial, as it will decrease $V_{l}$ (Daidzic, 2016b). An algorithm for standard atmosphere computation was used from Daidzic (2015). The effect of humidity on DA becomes progressively more important as air temperatures increase. 


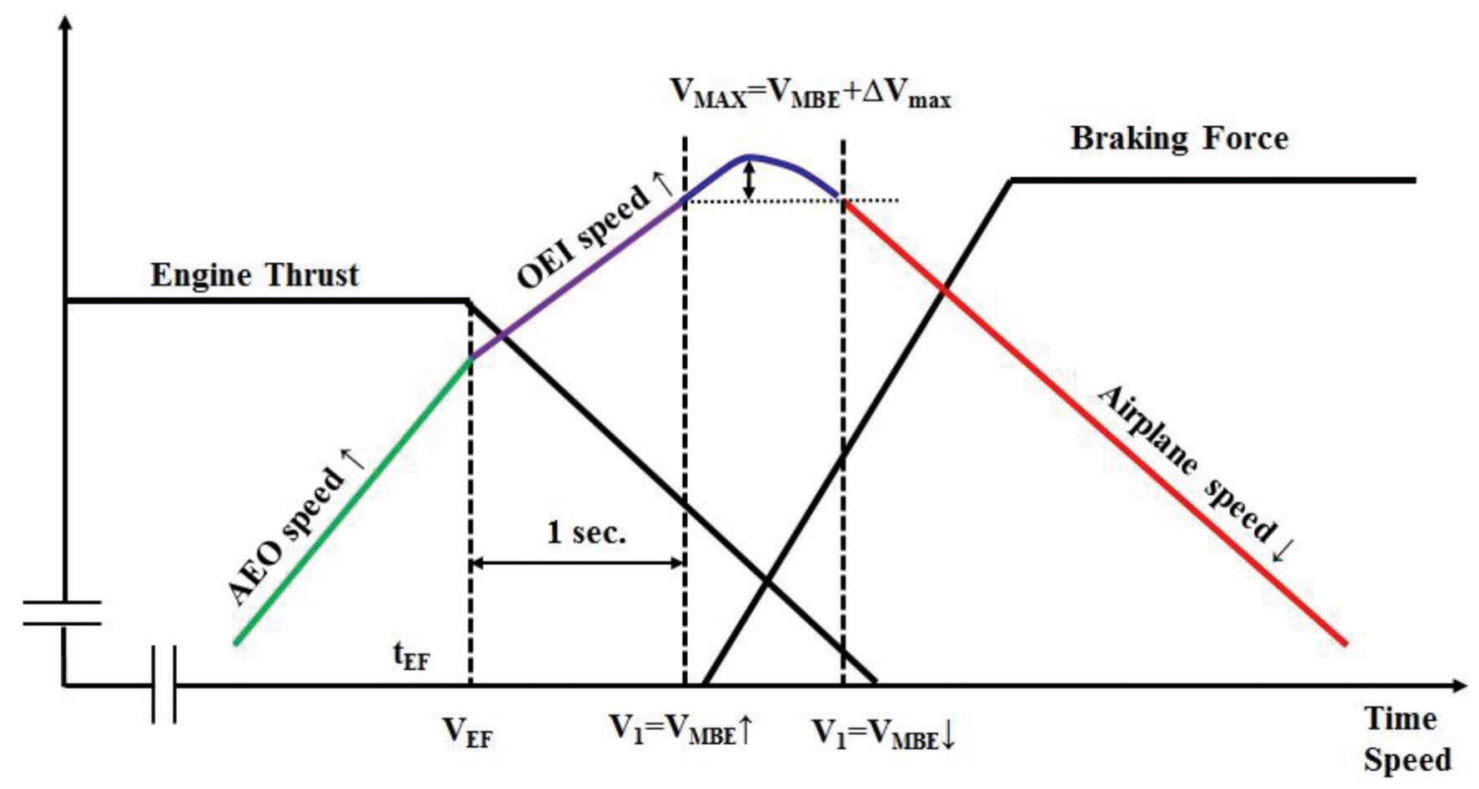

Figure 3. Engine failure and acceleration transition region. Not to scale.

The coefficient of added mass (Equation 4) actually increases somewhat for the reduced airplane mass/weight since the rotary inertia stays practically constant.

\section{Sensitivity of Maximum Braking Energy and Speed Estimation}

In the case of a level-runway no-wind scenario, the $V_{M B E}$ speed depends only on the airplane mass and the MBE. On the other hand, assuming thermal equilibrium and constant maximum allowed peak material temperatures, the MBE depends on the initial temperatures of brakes and the wear state of brakes (heat-stack mass). Using the theory of small linear perturbations, we can write for the MBE perturbation:

$$
\frac{\delta E_{M B E}}{E_{M B E}}=\frac{\delta M_{B}}{M_{B}}+\frac{\delta\left(\Delta T_{i}\right)}{\Delta T_{i}}
$$

According to Equation (19), if the brake heat-pack mass is reduced by $10 \%$ (say $33 \%$ wear) and the initial temperature difference is $10 \%$ lower than design, the MBE decreases by 20\%. Using Equations (17) and (19), the $V_{M B E}$ sensitivity can be expressed as:

$$
\begin{aligned}
\frac{\delta v_{M B E}}{v_{M B E}} & =\frac{1}{2} \frac{\delta E_{M B E}}{E_{M B E}}-\frac{1}{2} \frac{\delta M_{A}}{M_{A}} \\
& =\frac{1}{2}\left[\frac{\delta M_{B}}{M_{B}}+\frac{\delta\left(\Delta T_{i}\right)}{\Delta T_{i}}\right]-\frac{1}{2} \frac{\delta M_{A}}{M_{A}}
\end{aligned}
$$

For example, for an airplane with takeoff mass $6 \%$ lower than MSTOM and 66\% worn-out brakes (e.g., 20\% heatstack mass reduction) - and due to prolonged taxiing - the initial brake temperature difference is reduced by $20 \%$ (e.g., from $1,000-150=850{ }^{\circ} \mathrm{C}$ to $1,000-320=680{ }^{\circ} \mathrm{C}$ ); the $V_{M B E}$ reduction is $17 \%$. If the MBE speed for new and cool brakes at MSTOM is 180 KEAS, the new $V_{M B E}$ becomes 159 KEAS. After the 1988 RTO overrun accident, all T-category airplanes have been certified for the MBE AS using fully worn out brakes. Newer brakes obviously provide some inherent margins, but much also depends on the residual energy and taxiing thermal load.

\section{Thermal Energy Considerations During Frictional Braking}

Due to intense heating, brakes must be cooled (convective and radiative). However, for the short duration of maximum effort braking, we can assume that the entire mechanical energy is being absorbed by break discs. Thermodynamic equilibrium considerations lead to a simple relationship for temperature rise in brake discs, $\Delta T_{B}=E_{M B E} /\left(M_{B} \cdot c_{B}\right)$. To illustrate this, let us take an airplane that weighs $410,000 \mathrm{lbf}$ (mass is $186,364 \mathrm{~kg}$ ) taking off on a level dry runway and no wind. The airplane has eight wheels/tires in dual-axle configuration (four wheels per main landing gear bogie). The total effective heat-absorbing heat-pack mass of eight brakes, each consisting of five multiple-discs in a single heat stack is thus $2,000 \mathrm{~kg}(4,410 \mathrm{lbf})$. It was assumed that a single steel rotor-stator pair has a mass of $50 \mathrm{~kg}$ (each $25 \mathrm{~kg}$ neglecting the pressure plate). The rotary inertia added-mass coefficient is assumed to be conservative 1.01 ( $1 \%$ added mass). The brake discs are of low-grade carbon (1\%) steel with low steel content fiber-containing stators. We assumed averaged rotor/stator specific heat capacity of $480 \mathrm{~J} / \mathrm{kg} \mathrm{K}$ and density of steel of about $7,750 \mathrm{~kg} / \mathrm{m}^{3}$ (Holman, 1986). Let us calculate the uniform heat-stack temperature rise if the airplane performs RTO from maximum reached GS of 165 knots $(85 \mathrm{~m} / \mathrm{s})$. The energy that brakes must absorb in the form of thermal load 
using Equation (14) is then about $5.015 \times 10^{8} \mathrm{ft}-\mathrm{lbf}$, $6.799 \times 10^{8} \mathrm{~J}$ (about $680 \mathrm{MJ}$ ), or $118.86 \mathrm{kWh}$ distributed over 40 rotor-stator pairs $(1 \mathrm{ft}-\mathrm{lbf}=1.355828 \mathrm{Nm}$ or $\mathrm{J}$, and $1 \mathrm{Btu}=778.161 \mathrm{ft}-\mathrm{lbf})$. A thermal load is thus $85 \mathrm{MJ} / \mathrm{brake}$. The temperature increase in the heat pack is about $708{ }^{\circ} \mathrm{C}$. This means that each $\mathrm{MJ}$ of heat is responsible for a temperature increase of $8.33{ }^{\circ} \mathrm{C} /$ brake. If the initial brake temperature was $150{ }^{\circ} \mathrm{C}$ when takeoff commenced, the final will reach about $858{ }^{\circ} \mathrm{C}$ after RTO. This temperature increase is very slightly overestimated as no cooling is assumed during about 15 seconds of maximum-effort braking with the average deceleration of about $0.58 \mathrm{~g}$ and the braking distance of 2,081 ft. The average brake power converted into heat and ultimately dissipated into environment over 15 seconds is 45.327 MW (60,784 HP). For comparison, Airbus A330/340 uses design certified values of $105 \mathrm{MJ} / \mathrm{brake}$, while A320 has certified energy of $69 \mathrm{MJ} /$ brake. Some brakes have demonstrated significantly higher energy absorption characteristics during testing.

Assuming that alternating rotors and stators absorb most of the kinetic energy and that cooling of brake discs/rotors occurs through forced convection and radiation (at higher temperatures), we can write thermal balance in differential form as shown in Appendix C, where a lumped-parameter small Biot-number thermal model of disc brakes is developed. The model has a time-dependent forcing function in the form of variable mechanical braking power. This equation can be solved numerically with other ODEs (ordinary differential equations). However, with few assumptions, thermal ODE is linearized, resulting in decoupling from the system, and solved analytically. The exact solution of the disc thermal balance equation in the case of constant deceleration, physical, and thermodynamic parameters is provided in Appendix C. The lumped-parameter analysis implies small internal heat-conduction resistance as compared to outer convective and radiative thermal resistances. As a consequence, uniform internal temperature distribution exists at every instant.

The MBE can be thus defined in terms of the maximum allowable representative brake heat-stack temperature achieved ( $T \leq T_{\max }$ ) for initially cool brakes. Brake temperatures are usually depicted on dedicated cockpit displays and/or multifunction displays' synoptic pages (e.g., B777) to characterize brake temperatures for each wheel. The cockpit brake temperature indications do not necessarily show the actual disc temperature, but some related representative value chosen by the manufacturer. The hotter the brakes are before attempted takeoff, the less braking capacity is available if high-speed RTO is required.

\section{Brake Friction Materials and Fluids}

Some basic brake disc/rotor physical and thermal material properties, mostly at $20{ }^{\circ} \mathrm{C}$ and for aerospace use, are presented in Table 1 (Breuer \& Bill, 2008; Daidzic, 2016c; Holman, 1986; Özişik, 1985). Specific heat capacity, thermal conductivity, and temperature limits are preferred high, while thermal expansion is desirably low. Large variations in thermal properties exist depending on the exact composition of materials used. For example, SiliconCarbide ( $\mathrm{SiC}$ ) can have a specific heat capacity of 1,420 $\mathrm{J} / \mathrm{kg} \mathrm{K}$ at low temperatures. As the temperature increases to $2,000 \mathrm{~K}\left(1,727{ }^{\circ} \mathrm{C}\right)$, the specific heat capacity for manufactured graphite/carbon materials can be as high as $2,077 \mathrm{~J} / \mathrm{kg} \mathrm{K}$ ). A summary of brake materials used in civilian and military aircraft is also presented in Daidzic (2016c). For the purpose of comparison, passenger cars have brake discs manufactured from grey cast iron (GCI; iron-carbon alloys with $2.5-4 \%$ of Carbon and 1-3\% of Silicon) of qualities GCI 15 to GCI 25. Also, small amounts of Molybdenum and Chrome are added to give greater abrasion and cracking resistance (Breuer \& Bill, 2008). Stainless steels will have a minimum of $10.5 \%$ Chromium. Most common brake fluids in road vehicles are based on glycols, glycol ethers, and their borate esters (Breuer \& Bill, 2008). Antioxidants and corrosion inhibitors are added for improved performance. The boiling point of many commercially available automotive brake fluids is in the range of 210 to $250{ }^{\circ} \mathrm{C}$. For high-performance applications, Silicone ester-based brake fluids exhibit low viscosity behavior at low temperatures combined with relatively high fluid boiling points (Breuer \& Bill, 2008).

\section{B737 Brakes and Landing Gear}

Boeing 737-400 (classic series) is a 150,000 lbf (68 metric ton) MSTOW airplane. According to Brady (2016), the classic series B737 (300/400/500) brakes are made of steel-alloy (metal-ceramic) with the trade name Cerametalix ${ }^{\circledR}$, and with versions made by either Goodrich or Honeywell. Since 2008, the carbon-brake option has been available for the B737NG (Allen et al., 2009) from either UTC

Table 1

Comparison of some heat sink materials for disc brakes (Daidzic, 2016c).

\begin{tabular}{lcccc}
\hline Property & SS C-1\% & Cast Iron & Carbon & Beryllium \\
\hline Density $\left[\mathrm{kg} / \mathrm{m}^{3}\right]$ & 7,801 & 7,250 & 1,690 & 1,850 \\
Specific heat capacity $[\mathrm{J} / \mathrm{kg} \mathrm{K}]$ & 473 & 460 & 720 & 1,825 \\
Thermal conductivity $\left[\mathrm{W} / \mathrm{m}^{2} \mathrm{~K}\right]$ & 45 & 57 & 130 & 200 \\
Thermal expansion $[\mu \mathrm{m} / \mathrm{mK}]$ & 17 & 11 & 4 & 12 \\
Temperature limit $\left[{ }^{\circ} \mathrm{C}\right]$ & 1,150 & 1,100 & 2,200 & 930 \\
\hline
\end{tabular}




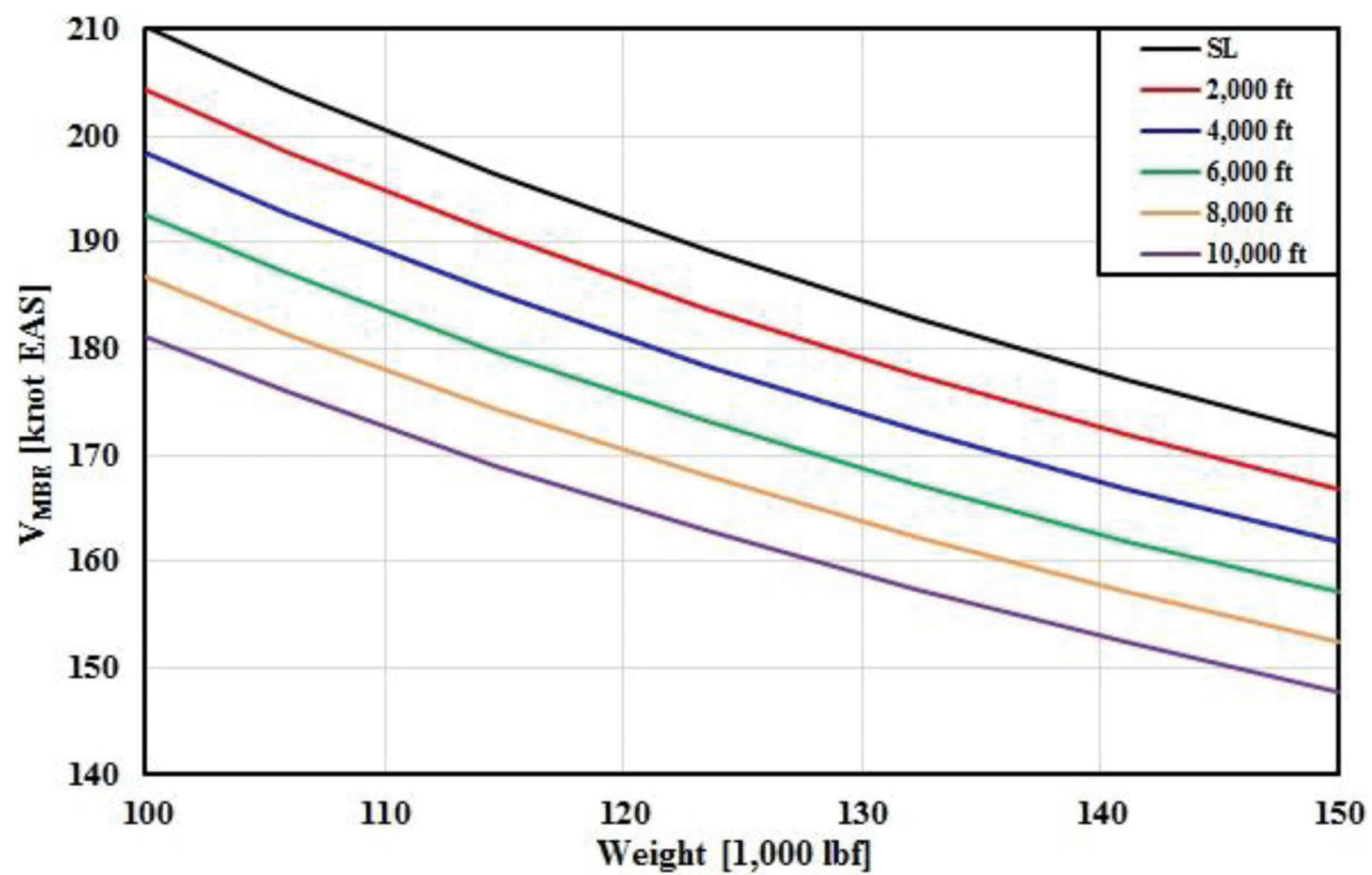

Figure 4. Computational results of $V_{M B E}$ for B737-400 with steel-alloy brakes at various pressure altitudes with standard temperatures, level runway, and no wind.

Aerospace systems (formerly Goodrich) with DURACARB ${ }^{\circledR}$ carbon technology, or $\mathrm{Safran}^{\odot}$ (formerly Messier-Bugatti) with SepCarb ${ }^{\circledR}$ III OR (Oxidant Resistant) technology. Carbon brakes on the B737NG are about $320 \mathrm{~kg}$ (706 lbf) lighter than steel brakes and last twice as long (Airbus, 2001; Allen et al., 2009; Brady, 2016). That also leads to lower fuel consumption and $\mathrm{CO}_{2}$ emissions reduction (Allen et al., 2009). We did not have access to design details of the B737-400 braking system, so many informed guesses were made. Four stainless-steel rotor-stator pairs per wheel are used in our computations. Each main landing gear has one axle with two braked wheels/tires (twin wheel design) resulting in 16 steel rotor-stator pairs, each of $250 \mathrm{~cm}$ radius and $30 \mathrm{~mm}$ thick when new. The maximum braking pressure for B737 series is 3,000 psi (Moir and Seabridge, 2008; Wild, 2008). Anti-skid is available with alternate brakes, but not touchdown or locked wheel protection on series before the B737NG (such as in B737-400).

\section{Results and Discussion}

The MBE capacity will be limited by the highest allowable representative temperature developing on the rotorstator interface and the onset of serious brake fade (see Appendix C). Based on the calculated MBE available, the maximum breaking energy speed in terms of KEAS for existing air density, wind, and runway slope is calculated and compared with published aircraft data (AFM).
Computations of the $V_{M B E}$ for B737-400 airplanes equipped with steel-brakes as a function of TOW, and various DAs as parameters for dry \& level runway and no wind, are shown in Figure 4. Equation (18) was used to estimate MBE speed (EAS/CAS). Standard temperatures and barometer setting are used so that MSL elevation (local Geoid height), PA (pressure altitude), and DA are all equal. The added-mass coefficient due to rotary components was estimated and assumed constant at $k=1.005$. Design MBE capacity of B737-400 new steel brakes is set to $1.97 \mathrm{E}+08$ ft-lbf (2.671E+08 J or $267 \mathrm{MJ})$. This implies about $67 \mathrm{MJ} /$ brake. Design MBE also agrees well with the old FAR 25 method (Equation 1).

In order to verify the fidelity and the accuracy of the presented MBE model, the AFM data of $V_{M B E}$ for a B737400 was used as a reference (CAA, 2006). Three different PAs were used (SL, 3,600, and 7,500 ft). They correspond to air density ratios $\sigma$ of $1.0,0.9$, and 0.8 , respectively. Since the data were taken directly from the B737 AFM $V_{M B E}$ graphs, we estimated maximum reading (parallax) errors of \pm 2.5 knots for speed and $\pm 1,000 \mathrm{lbf}(454 \mathrm{~kg}$ ) for weight and existing PAs and ambient temperatures. The graphical presentation of experimental AFM data, power trends (with associated $\mathrm{R}^{2}$ goodness-of-the-fit measure), and the $V_{M B E}$ computations are presented in Figure 5. Error bars are depicted for each AFM measured value. The model computational results using the MBE of $1.970 \times 10^{8} \mathrm{ft}-1 \mathrm{bf}$ and constant added-mass coefficient of $k=1.005$ are 


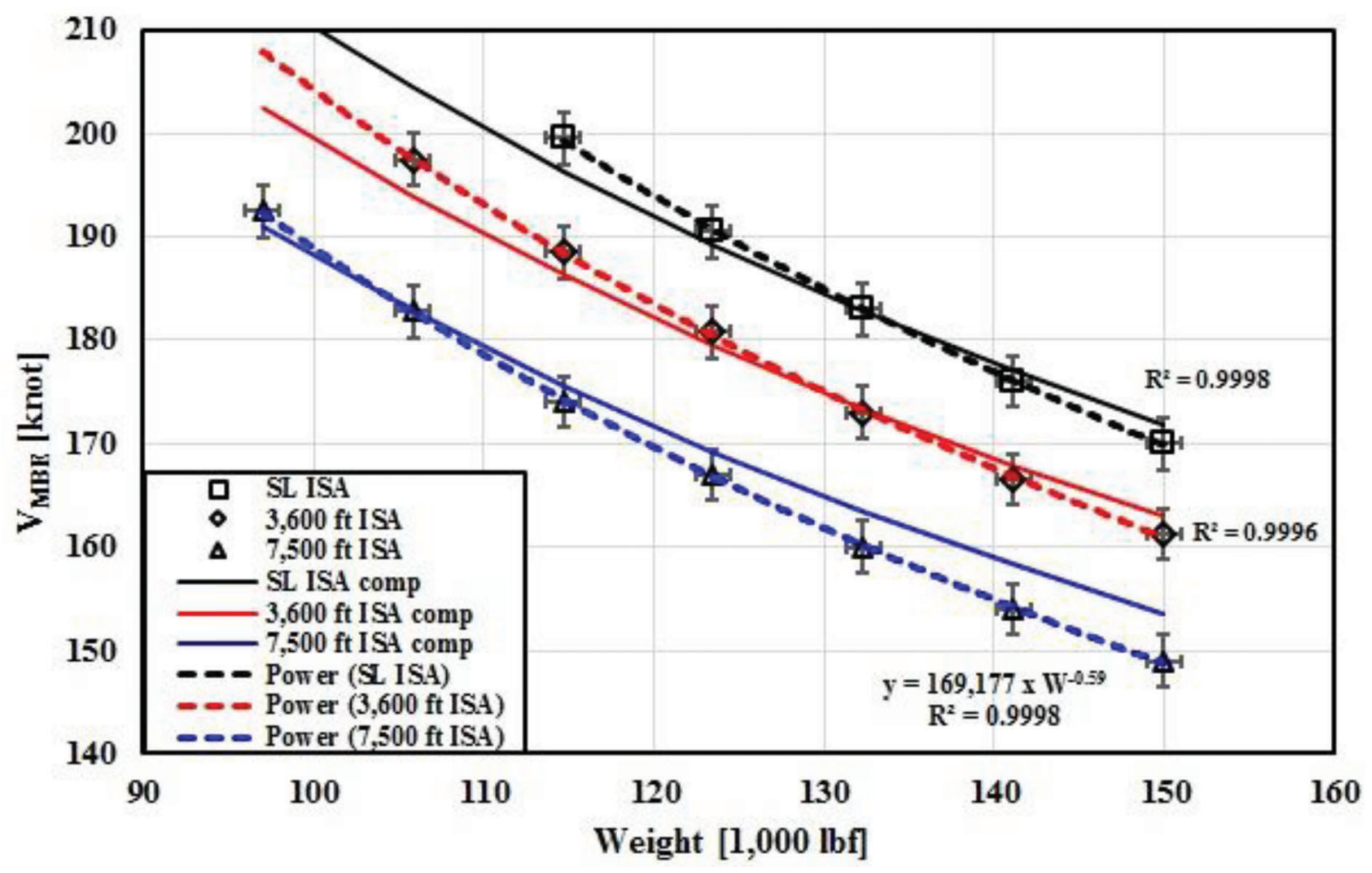

Figure 5. Experimental (AFM) and computational results of $V_{M B E}$ for B737-400.

shown in bold lines. The computational results are in decent agreement with the measured results for all three different altitudes. The largest absolute error occurs at $7,500 \mathrm{ft}(\sigma=0.8)$ for maximum weight of 68 tons (or $150,000 \mathrm{lbf}$ ) and is 4.60 knots. The least-square powertrend of measured AFM data not only falls within the error bars, but the approximation is almost perfect. Based on the power-trend approximation, the $V_{M B E}$ happens to be a function of $\mathrm{W}^{-0.59}$, while theory derived here implies $\mathrm{W}^{-0.50}$ dependence. The AFM certified data power-trends for B737-400 are thus steeper than model predictions. The reason could be that transition region was not properly accounted for, and there may be a small dependence of aircraft mass, which would explain a steeper drop in MBE speed with TOW. Additionally, it is not clear what inherent margins the manufacturer used when establishing MBE speeds. To reiterate, the full MBE capacity is only available with initially cool brakes. Nevertheless, the model predictions are quite decent considering its simplicity.

Boeing's B737-400 AFM further requires corrections for average runway slope and wind for $V_{M B E}$. For every 10 knot HW, the $V_{M B E}$ is increased by 3 knots. Note that FAR 25 requires no more than $50 \%$ accounting for HW, so this correction contains additional safety margins. For every 10 knot TW, the $V_{M B E}$ is decreased by 20 knots, which is essentially a $200 \%$ safety margin and more than required by regulations $(150 \%)$. The uphill slope (positive gradient) results in a $V_{M B E}$ increase of 2 knots for every $1 \%$ effective gradient, while each $1 \%$ downhill gradient (downslope) requires a $V_{M B E}$ decrease of 5 knots. For each knot where $V_{l}$ is larger than $V_{M B E}$, the aircraft weight must be reduced by $300 \mathrm{~kg}(660 \mathrm{lbf})$. Clearly, additional safety margins are provided in AFM, which makes the computations of operational MBE speeds simple but overly conservative. The results and comparison of $V_{M B E}$ model computations and the measured AFM data with corrections for operating conditions are depicted in Figure 6.

The manufacturer clearly uses additional margins to account for TW $(200 \%$ instead of the minimum required $150 \%$ ). Also, additional HW margin was used (30\% instead of the maximum 50\% HW credit). Additionally, large margins were used for sloped runways. Accounting for sloped runways is tricky. What really matters is only the braking distance, which is usually only the last quarter or third of the ASDA. Even though the average runway gradient may be negative, the deceleration portion may be positive assisting braking. The opposite and worse condition exists for average upslope runway, but the last portion is downhill, actually resulting in longer braking distance and lower $V_{M B E}$. The local slope data is almost never used in calculations. Using the actual braking length (about 2,250 ft) resulted in higher MBE speeds than the B737-400 AFM data. But when we used the total ASDA distance and constant negative slope of $2 \%$, we came very close to published data. Maybe that is coincidence or perhaps the way the manufacturer adjusted its $V_{M B E}$ speeds. Historically, operational corrections used simple rules, which often were excessively conservative. 


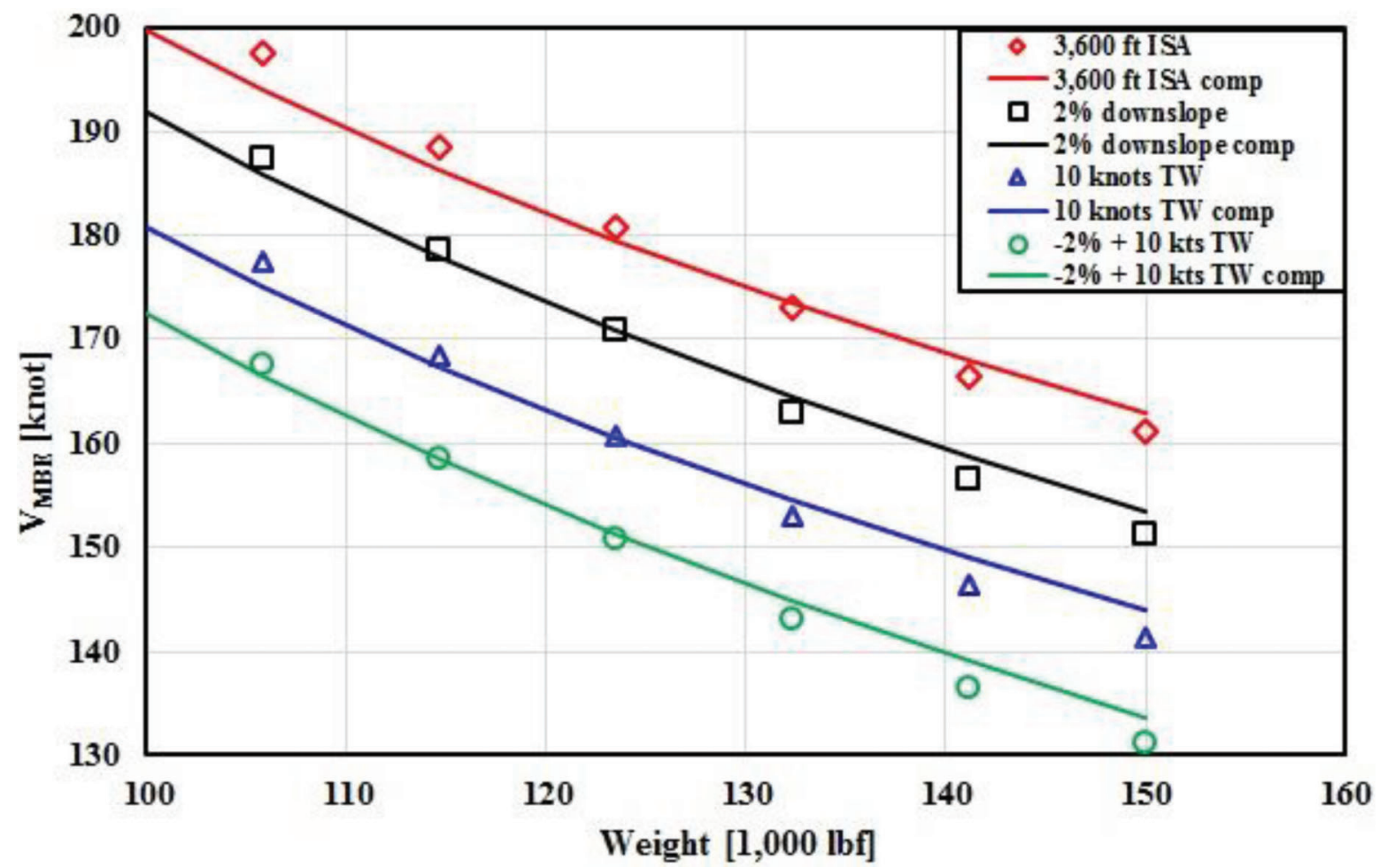

Figure 6. Experimental (AFM) and computational results of $V_{M B E}$ for B737-400 at about 3,600 ft in the case of individual and combined tailwind (TW) and $2 \%$ downslope effects.

Table 2

Summary of brake design parameters used for calculations (fictional B737-400 brakes).

\begin{tabular}{|c|c|c|c|c|c|c|c|}
\hline \multirow{2}{*}{$\begin{array}{l}n_{w} \\
{[-]}\end{array}$} & \multirow{2}{*}{$\begin{array}{l}n_{B} \\
{[-]}\end{array}$} & \multirow{2}{*}{$\begin{array}{c}R_{\text {Bdisc }} \\
{[\mathrm{m}]}\end{array}$} & \multirow{2}{*}{$\begin{array}{c}c_{B} \\
{[\mathrm{~J} / \mathrm{kg} \mathrm{K}]}\end{array}$} & \multirow{2}{*}{$\begin{array}{c}\rho_{B} \\
{\left[\mathrm{~kg} / \mathrm{m}^{3}\right]}\end{array}$} & \multirow{2}{*}{$\begin{array}{l}\text { \# Rotors } \\
\text { and Stators }\end{array}$} & \multicolumn{2}{|c|}{ Rotor/Stator discs [mm] } \\
\hline & & & & & & $0 \%$ wear & $100 \%$ wear \\
\hline 2 & 4 & 0.250 & 480 & 7,780 & $4+5$ & $30 / 30$ & $22 / 22$ \\
\hline
\end{tabular}

Thermal and speed computations for B737-400's new ( $0 \%$ wear) steel-alloy brakes are shown in Figure 7 for various braking initiation speeds (150, 160, and 170 knots) and two different weights of 65 and 68 metric tons $(143,325$ and $150,000 \mathrm{lbf})$. The initial temperature of brake discs is $400 \mathrm{~K}$ (about $127{ }^{\circ} \mathrm{C}$ ). The constant enclosure (ambient) temperature for radiative and convective heat transfer is $77{ }^{\circ} \mathrm{C}(350 \mathrm{~K})$. Negative constant average braking acceleration of $5.6 \mathrm{~m} / \mathrm{s}^{2}$ was used; level runway and no wind was assumed. Design parameters for imaginary brakes used are summarized in Table 2 .

Airplane auto-brake systems (ABS) maintain constant deceleration, so this simulation scenario is not without merit. The linear speed history is shown for the 170-knots initial speed only. It took about 15.62 seconds to stop the airplane. The maximum heat-stack temperature reached is $880.55{ }^{\circ} \mathrm{C}$ just before the stop. Magnitude of braking deceleration plays only a minor role in attaining maximum temperatures. Varying deceleration from 5 to $6 \mathrm{~m} / \mathrm{s}^{2}$ (starting from initial 170 knots) only resulted in maximum temperature change of $1-2 \mathrm{~K}$. Cooling is a minor factor during braking. Only when the airplane is about to stop and very little motion energy is absorbed, cooling causes miniscule brake temperature decrease. Halving combined convection/radiation heat transfer coefficient from the original 100 to $50 \mathrm{~W} / \mathrm{m}^{2} \mathrm{~K}$ only resulted in slightly higher brake temperatures $\left(889.06^{\circ} \mathrm{C}\right.$ at 170 knots and $\left.-5.6 \mathrm{~m} / \mathrm{s}^{2}\right)$. Thus, cooling is of little help during braking. Only when braking ends does cooling manage to decrease brake temperatures. Braking distance is calculated from the speed-time history:

$$
\begin{gathered}
L_{B}=\int_{0}^{L_{B}} d x=\int_{0}^{t_{B}} v(t) d t=\bar{v} \cdot t_{B}=v_{0} \int_{0}^{t_{B}} d t-\int_{0}^{t_{B}} a(t) \cdot t d t \\
v(t)=v_{0}-a(t) \cdot t
\end{gathered}
$$

In the case of constant deceleration, the braking distance becomes:

$$
L_{B}=\int_{0}^{v_{0}} v(t) \frac{d v}{a}=\frac{v_{0}^{2}}{2 \cdot a}=v_{0} \cdot t_{B}-a \cdot \frac{t_{B}^{2}}{2}=\frac{v_{0} \cdot t_{B}}{2}
$$

For example, for a 15.6 seconds braking duration, starting speed of 170 knots $(87.51 \mathrm{~m} / \mathrm{s})$, and constant-deceleration 


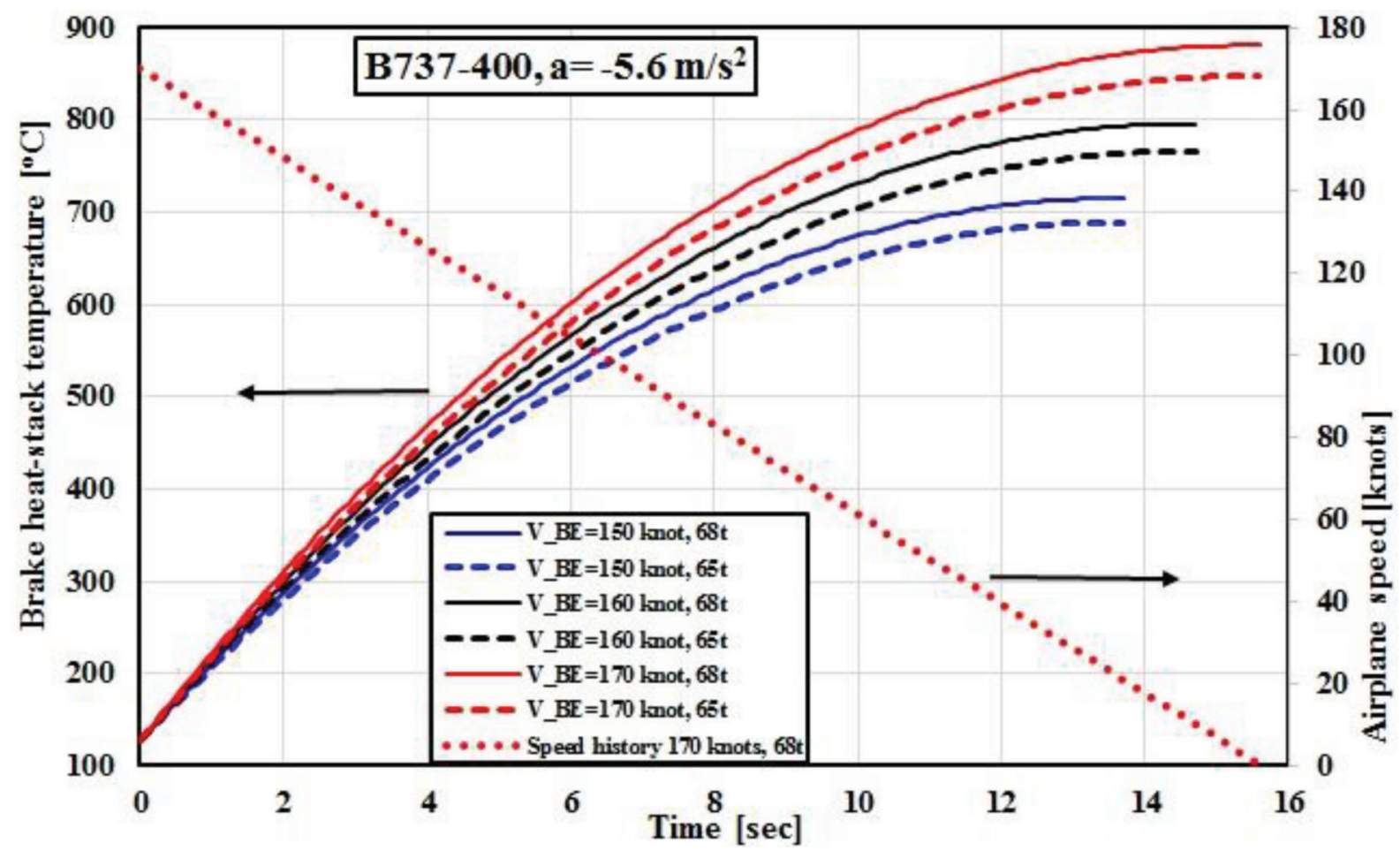

Figure 7. Temperature and speed histories for a B737-400 with brand new brakes ( $0 \%$ friction elements mass loss or wear) and different RTO brake-energy speeds at constant deceleration.

of $5.6 \mathrm{~m} / \mathrm{s}^{2}(0.571 \mathrm{~g})$, the braking distance according to Equation (22) becomes $683.75 \mathrm{~m}(2,243.25 \mathrm{ft})$. Numerical integration algorithm returned the value of $683.79 \mathrm{~m}$, a mere $4 \mathrm{~cm}$ absolute error. This test was also used to validate numerical integration method embedded in our computational programs.

As the brakes continuously wear in service, the friction lining and the heat-pack/stack mass is slowly decreasing. That results in lowered heat-storage capacity and increased heat-stack temperatures. However, as shown in Appendix B, high friction-material temperatures result in lower friction coefficients (brake fade), which then reduces maximum possible braking torque and consequently increases stopping distances. Thus thermal computations for $100 \%$ uniformly worn-out brakes $(22 \mathrm{~mm}$ disc rotor and stator thickness each remaining, or $26.67 \%$ brake heat-stack mass loss) is shown in Figure 8. The highest temperature in SS brakes is now $1,148.59^{\circ} \mathrm{C}$, which is just about the material temperature limit for SS brakes (see Table 1). Due to brake fade (Appendix B), average deceleration is now $5.0 \mathrm{~m} / \mathrm{s}^{2}$, and it takes this 68 metric ton airplane 17.51 seconds to stop, about 2,513 ft, i.e., about $270 \mathrm{ft}$, longer and almost 2 seconds more than with the new brakes. Certified ASDR distances are based on the fully worn-out brakes. The main results of computations for new and $100 \%$ worn-out brakes are summarized in Table 3.

To estimate the time required for brake cooling after application, we used a theory presented in Appendix C. Computational results for different cooling efficiencies are summarized in Figure 9. One of the cooling scenarios uses B737-400 steel-alloy brakes, but now with the average combined heat transfer coefficient of $50 \mathrm{~W} / \mathrm{m}^{2} \mathrm{~K}(D=$ 0.001 ), to simulate reduced efficiency of ventilated rotors due to dirt accumulation and corrosion. The cooling halftime or time required to cool brakes to half of their initial temperature $\left(T_{o}\right)$ of $800{ }^{\circ} \mathrm{C}$ for the constant ambient temperature $T_{\infty}$ of $100{ }^{\circ} \mathrm{C}$ is about 14 minutes provided no other thermal energy inputs. If the heat transfer coefficient reduces further to $25 \mathrm{~W} / \mathrm{m}^{2} \mathrm{~K}(D=0.0005)$, it will take over 28 minutes to lower temperature from $800{ }^{\circ} \mathrm{C}$ to 400 ${ }^{\circ} \mathrm{C}$, or 65 minutes to cool the brakes from $800{ }^{\circ} \mathrm{C}$ to $200{ }^{\circ} \mathrm{C}$. Heat transfer coefficients (from 10 to $100 \mathrm{~W} / \mathrm{m}^{2} \mathrm{~K}$ ) simulating various natural- or free- and forced-convection cases could be considered to mimic different operational cooling scenarios.

Thermal energy absorption is directly proportional to the mass of the heat stack. As brake wear progresses and the friction material is lost, the temperature of the heat pack will increase for the same braking energy used. Temperature increase in the heat stack due to loss of its mass is estimated using linear perturbations:

$$
\frac{\delta(\Delta T)}{\Delta T}=-\frac{\delta M_{B}}{M_{B}}
$$

For $10 \%$ loss of friction mass due to wear, the temperature difference will increase by $10 \%$. For example, if the MBE heating of the brake's heat stack resulted in an 


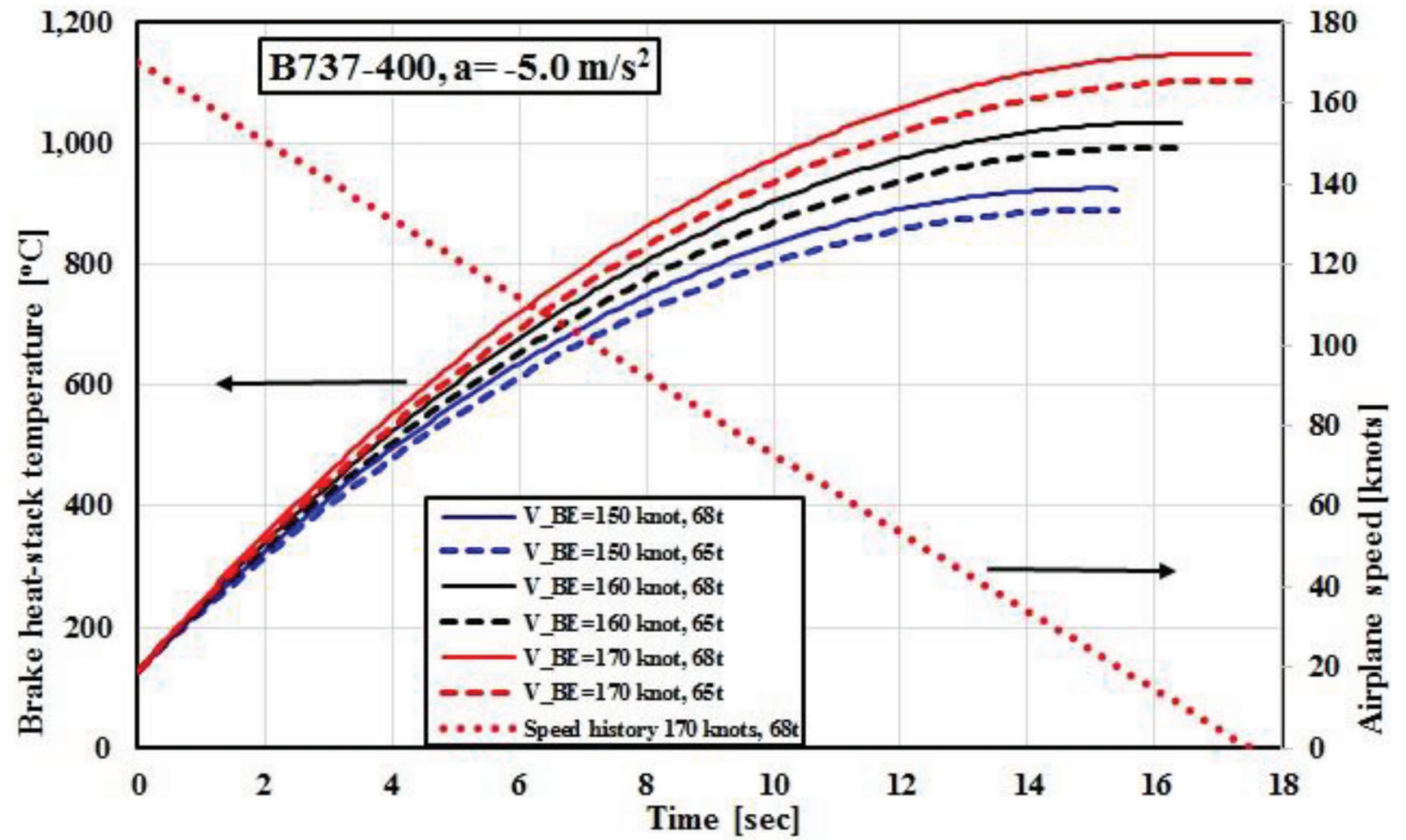

Figure 8. Temperature and speed histories for a B737-400 at 100\% worn-out brakes (26.67\% friction elements mass loss) and different RTO brake-energy speeds at constant deceleration.

Table 3

Summary of main results for the new and $100 \%$ worn-out brakes $126.67 \%$ friction elements mass loss) for B737-400's RTO at 68 tons, 170 knots, and initial brake temperature of $126.85^{\circ} \mathrm{C}$.

\begin{tabular}{lcc}
\hline Multiple-Disc Brake condition & $\begin{array}{c}\text { New } \\
(0 \% \text { wear })\end{array}$ & $\begin{array}{c}\text { Replace } \\
(100 \% \text { worn-out })\end{array}$ \\
\hline Braking time $[\mathrm{sec}]$ & 15.62 & 17.51 \\
Braking distance $[\mathrm{ft}]$ & $2,243.37$ & $2,512.58$ \\
Peak temperature $\left[{ }^{\circ} \mathrm{C}\right]$ & 880.55 & $1,148.59$ \\
Brake temperature increase $\left[{ }^{\circ} \mathrm{C}\right]$ & 753.70 & 1021.74 \\
Average deceleration $\left[\mathrm{m} / \mathrm{s}^{2}\right]$ & 5.6 & 5.0 \\
Rotor+Stator thickness $[\mathrm{mm}]$ & $30+30$ & $22+22$ \\
\hline
\end{tabular}

$800{ }^{\circ} \mathrm{C}$ increase with the new brakes, $10 \%$ worn brakes will experience an $880{ }^{\circ} \mathrm{C}$ temperature increase starting with equally cool brakes. Up to $30 \%$ loss of heat-pack (stack) mass is possible until the brakes are considered fully worn (Arampatzis, 2013). In our particular case, the brake's heatpack mass loss of $26.67 \%$ will result in a $26.67 \%$ temperature rise $\left(213.36{ }^{\circ} \mathrm{C}\right)$ and final temperature of $1,013.36{ }^{\circ} \mathrm{C}$.

From the previous analysis it follows that the representative brake temperature just before takeoff is a crucial safety parameter. As the mass of heat stack $\left(M_{B}\right)$ decreases, the final temperatures will be increasing for the same amount of energy absorbed. Elevated brake temperatures will result in somewhat faster cooling, but as was seen earlier during the short braking period, cooling is a minor factor. Thus, we should talk about the operationally available braking energy (ABE) capacity at every instant. ABE is dependent on the initial brake temperature $\left(T_{B i}\right)$ and existing $M_{B}$. In that respect $V_{M B E}$ is a direct function of $\mathrm{ABE}$. The maximum allowable design brake temperature $\left(T_{B, \max }\right)$ is constant, and higher $T_{B i}$ only reduces $\mathrm{ABE}$ and progressively more so as breaks wear. Residual brake energy (RBE) defines already stored thermal energy in brakes and depends on $T_{B i}$. As $M_{B}$ is slowly decreasing due to wear, the same RBE amount will be reflected in progressively higher $T_{B i}$. Taxiing necessitates use of brakes, and taxiing brake energy (TBE) further reduces ABE. For example, A320 increases thermal load on the brakes by about $5 \mathrm{MJ}$ during standard taxiing. The relationship between the $\mathrm{MBE}, \mathrm{ABE}, \mathrm{RBE}$, and $\mathrm{TBE}$ as a function of brake temperature and brake wear is illustrated in Figure 10. Different wear states are characterized by changing slopes of the energy-temperature lines. In all this analysis we assumed constant specific heat coefficient, which is only an approximation. Mathematically, the wear-slopes are equal to $\tan ^{-1}\left(M_{B} c_{B}\right)$. We can now write:

$$
\begin{aligned}
& A B E\left(T_{i}\right)=M B E-R B E\left(T_{i}\right)-T B E \\
& v_{M B E}=f(A B E)
\end{aligned}
$$

If significant RBE remains from a previous landing, the $\mathrm{ABE}$ is reduced. Design MBE essentially exists only for cool brakes (manufacturer's designated $T_{B i}$ ). Newer brakes provide significant braking reserve, but $T_{B, \max }$ should never be exceeded, otherwise serious fade and brake (structural) failure results. COF between brake rotors and stators decreases rapidly with higher temperatures causing accelerated 


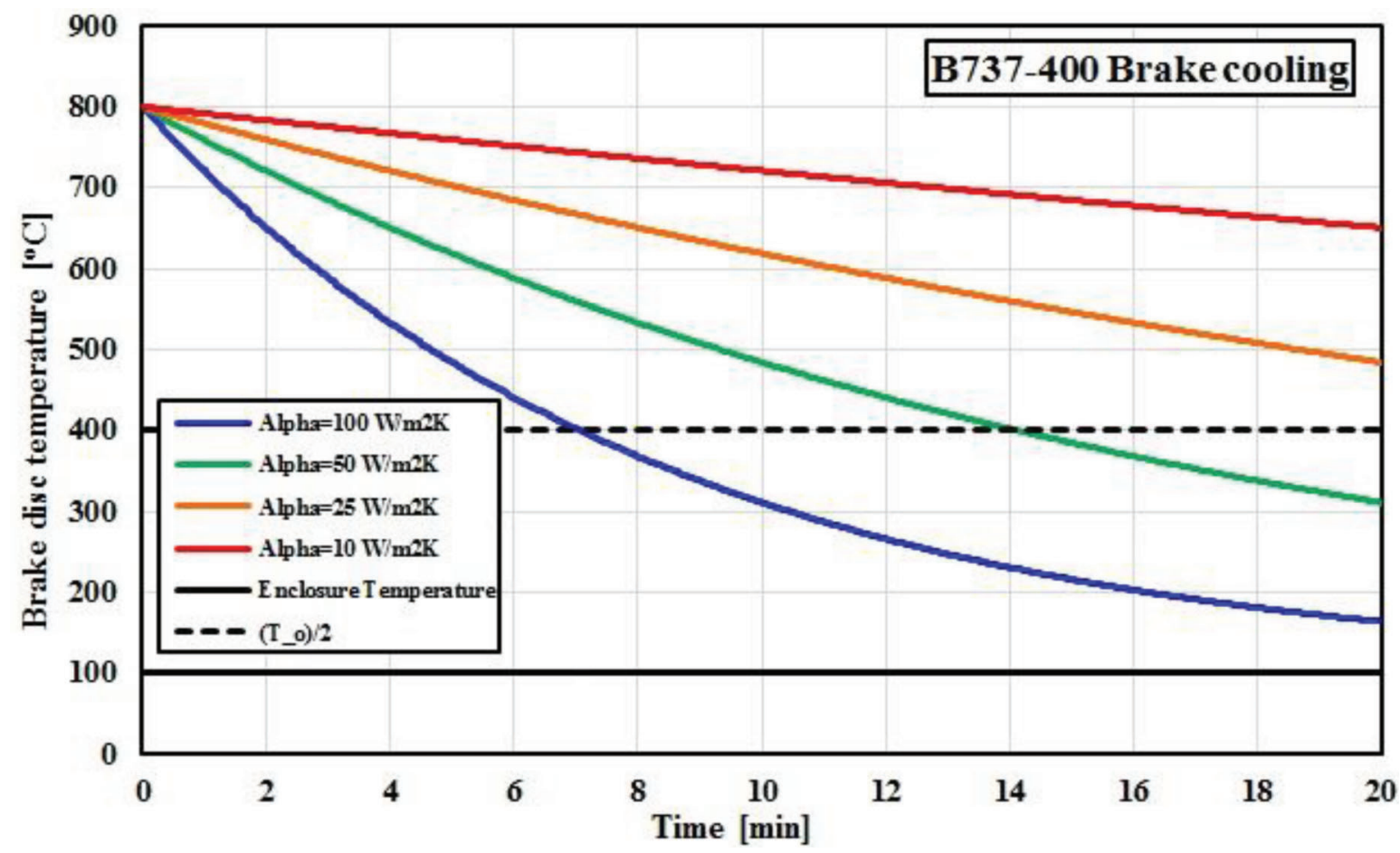

Figure 9. Brake cooling for steel-alloy B737-400 brake model as a function of time and different cooling efficiencies.

brake fade with dramatically increasing stopping distance. Additionally, if the hydraulic lines are not properly thermally shielded, the hydraulic fluid may start evaporating, resulting in almost complete loss of braking action.

To augment brake cooling, brake fans are often incorporated into wheel hubs. Also, one of the standard operational/piloting techniques to cool hot brakes is, socalled, delayed-retraction method. It implies leaving landing gears extended (provided obstacle clearance is not an issue) to cool brakes before retracting. Landing gears could be re-extended after obstacles are cleared. Landing gears can be also extended earlier (early-extension method) during the approach and landing phase for additional cooling, especially for quick-turnaround flights. Forced convection due to induced relative airflow in flight is an order of magnitude more efficient than cooling brakes while in wheel wells or stationary on the ramp (mostly free convection). Brake temperature should typically remain below $150{ }^{\circ} \mathrm{C}$ before attempting takeoff. High-speed RTO is always a possibility. While carbon brakes sustain and operate at higher temperatures, there is a danger of direct contact with such hot brakes. It is not uncommon to have carbon brakes heated above $1,400{ }^{\circ} \mathrm{C}$. Radiation shields must be installed to protect tires and other wheel/brake components from getting thermal overloads. Retracting landing gear while the brakes are still hot could cause a fire hazard in the wheel wells.

Future MBE model improvements may include detailed treatment of the acceleration transition region during RTOs, variable added-mass coefficient, advanced ODE solvers, inclusion of the anti-skid controller logic (e.g., propor- tional-integral-derivative, or PID, control), full brake-fade models, full nonlinear models, and more detailed acceleration models as a function of instantaneous forces and weight balance. A lumped-parameter thermal model can be extended to one or two spatial dimensions (distributed models). Future contribution may also involve detailed multiphysics 3D spatio-temporal temperature and stress distribution. Thermal stresses are of particular importance in brake disc designs. Computational multiphysics programs, such as ANSYS ${ }^{\circledR}$ or $\mathrm{COMSOL}^{\circledR}$ Multiphysics, can be used for more detailed thermal load distributions in brake systems. We already have several in-house developed heat transfer/exchange simulation models (in Fortran 95/03/08, Matlab, and True Basic) for various geometries that could be utilized for spatially distributed temperature and thermal stress computations. However, in such cases the exact geometric and design characteristics of particular airplane brakes would be required for high-fidelity computations. Such proprietary design information would be difficult to obtain. Ultimately, all real brake designs must be verified by dynamometer and actual flight tests. A lot of what is learned from brake models can be directly implemented in piloting and operational procedures.

\section{Conclusions}

In this article, the theoretical model of the maximum braking energy and the related $V_{M B E}$ speed for T-category airplanes was developed. The total kinetic energy of an airplane includes translational and rotary kinetic energy and the potential height-energy component for sloped runways. 


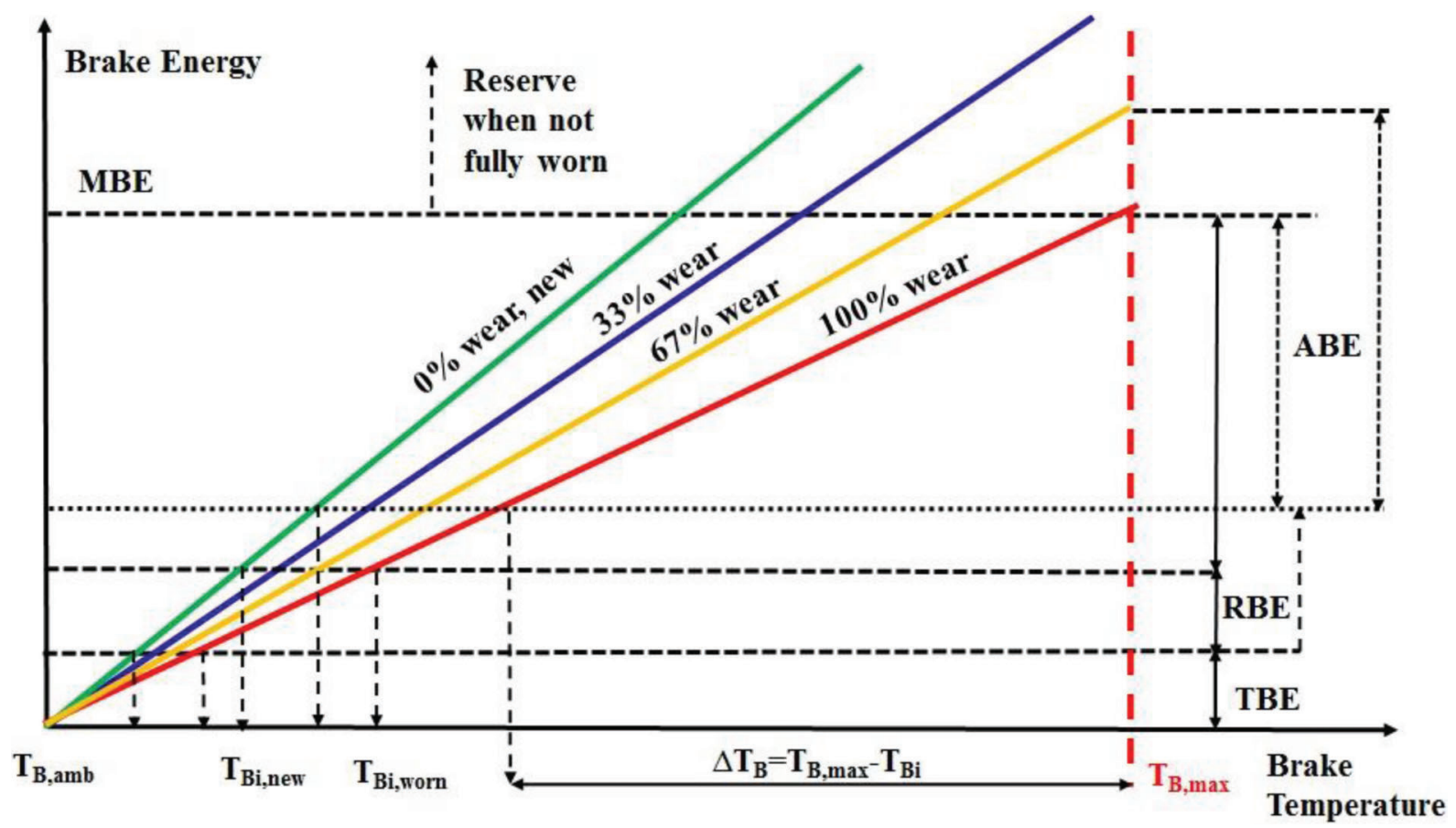

Figure 10. Braking energy considerations regarding brake heat-pack temperature for various brake wear states. Not to scale.

Time-dependent airplanes' mechanical power expression has been derived. The brake thermal model is based on a lumped-parameter analysis of ventilated brake heat packs. The thermal model is based on the small Biot-number lumped-parameter approximation and sufficiently describes the basic physics of the friction braking. The nonlinear differential equations of motion and the differential thermal model are coupled. A nonlinear set of ordinary differential equations incorporating tire slip can be solved numerically. A simple linear airplane braking model using average parameters and coefficients was developed for the first time to the best of our knowledge. The analytical solution for the constant deceleration thermal problem was derived. Additionally, the semi-empirical expression of temperaturedependent COF on a rotor-stator pair has been proposed. The presented mathematical model enables determination of the entire history of translational and angular accelerations and speeds, longitudinal distance, forces, torques, and disc temperatures during braking. Weight transfer during dynamic braking has been implemented in brake force determination. Added mass due to rotary inertia of spinning components has been incorporated and assumed constant for simplicity. Added mass for rotary inertia is indeed very small for airplanes. A theoretical model of $V_{M B E}$ which includes densityaltitude, runway slope, and wind effects as parameters has been developed for the first time to the best of our knowledge. A comparison of the theoretical $V_{M B E}$ model showed good agreement with the measured and approved AFM data for the B737-400 airplane at different DAs with and without, individual and combined, runway slope and tailwind effects.

\section{References}

Abell, M. L., \& Braselton, J. P. (2010). Introductory differential equations with boundary value problems (3rd ed.). Amsterdam, Netherlands: Elsevier Academic Press.

Agrawal, S. K. (1986). Braking performance of aircraft tires. Progress Aerospace Sciences, 23(2), 105-150. http://dx.doi.org/10.1016/03760421(86)90002-3

Airbus. (2001). A320 family instructor support (Flight operations support and line assistance). Blagnac, France: Author.

Airbus. (2002). Getting to grips with aircraft performance (Flight operations support and line assistance). Blagnac, France: Author.

Allen, T., Miller, T., \& Preston E. (2009). Operational advantages of carbon brakes. Aeromagazine, 3-2009(35). Seattle, WA: Boeing.

Alroqi, A. A., \& Wang, W. (2015). Comparison of aircraft tire wear with initial wheel rotational speed. International Journal of Aviation, Aeronautics, and Aerospace (IJAAA), 2(1), 1-30. http://dx.doi.org/10. 15394/ijaaa.2015.1043

Amiri, M., \& Khonsari, M. M. (2010). On the thermodynamics of friction and wear-A review. Entropy, 12, 1021-1049. http://dx.doi.org/ 10.3390/e12051021

Arampatzis, S. (2013). Brake energy: Operational considerations. Blue Skies GainJet Aviation Safety Magazine, 5. Athens, Greece: GainJet Aviation S. A.

Boeing Commercial Airplanes. (2005). 767 Airplane characteristics for airport planning (D6-58328). Seattle, WA: Author.

Boeing Commercial Airplanes. (2013). 737 Airplane characteristics for airport planning (D6-58325-6). Seattle, WA: Author.

Brady, C. (2016). The Boeing 737 technical guide. Retrieved from http:// www.b737.org.uk/

Breuer, B., \& Bill, K. H. (2008). Brake technology handbook (translated from 2006 German original). Warrendale, PA: Society of Automotive Engineers International (SAE).

Burckhardt, M. (1993). Fahrwerktechnik: Radschlupfregelsysteme. Würzburg, Germany: Vogel-Verlag. 
Canudas-de-Wit, C., Tsiotras, P., Velenis, E., Basset, M., \& Gissinger, G. (2003). Dynamic friction models for road/tire longitudinal interaction. Vehicle System Dynamics, 39(3), 189-226. http://dx.doi.org/10.1076/ vesd.39.3.189.14152

Carslaw, H. S., \& Jaeger, J. C. (1959). Conduction of heat in solids $\left(2^{\text {nd }}\right.$ ed.). Oxford, UK: Oxford University Press.

Chapman, F., Kornstaedt, L., \& Lignee, R. (2014, January). Airbus brake testing. Airbus Safety Magazine, 17. Blagnac, France: Airbus.

Civil Aviation Authority (UK CAA). (2006). CAP 698 CAA JAR-FCL examinations: Aeroplane performance manual (3rd ed.). West Sussex, UK: Author.

Creech, D. E. (1968). Aircraft brake energy analysis procedures. Technical Report ASD-TR-68-56. Dayton, OH: Wright-Patterson Air Force Base.

Daidzic, N. E. (2014). A total-energy based model of airplane overspeed takeoffs. International Journal of Aviation Aeronautics Aerospace (IJAAA), 1(3), 1-25. http://dx.doi.org/10.15394/ijaaa.2015.1016

Daidzic, N. E. (2015). Efficient general computational method for estimation of standard atmosphere parameters. International Journal of Aviation Aeronautics, and Aerospace, 2(1), 1-35. http://dx.doi.org/ 10.15394/ijaaa.2015.1053

Daidzic, N. E. (2016a). Determination of rejected landing roll runway point-of-no-return and go-around in transport category airplanes. International Journal of Aviation Aeronautics Aerospace (IJAAA), 3(1), 1-31. http://dx.doi.org/10.15394/ijaaa.2015.1110

Daidzic, N. E. (2016b). Optimization of takeoffs on unbalanced fields using takeoff performance tool. International Journal of Aviation Aeronautics Aerospace (IJAAA), 3(3), 1-53. http://dx.doi.org/10.15394/ ijaaa.2015.1129

Daidzic, N. E. (2016c, November). Aircraft stopping systems. Professional Pilot, 50(11), 86-92.

Daidzic, N. E., \& Shrestha, J. (2008). Airplane landing performance on contaminated runways in adverse conditions. Journal of Aircraft, 45(6), 2131-2144. http://dx.doi.org/10.2514/1.38056

Davies, D. P. (1971). Handling the big jets (3rd ed.). London: Civil Aviation Authority.

Davies, M. (Ed.). (2003). The standard handbook for aeronautical and astronomical engineers. New York: McGraw-Hill.

de Lemos Viana, J. P. R. (2011). Takeoff and landing performance optimization: Development of a computational methodology (Master's thesis, Instituto Superior Tecnico, Universidade Tecnica de Lisboa, Lisbon, Portugal). Retrieved from https://fenix.tecnico.ulisboa.pt/

Dixon, J. C. (1996). Tires, suspension and handling (2nd ed.). Warrendale, PA: Society of Automotive Engineers International (SAE).

Durbin, E. J., \& Perkins, C. D. (Eds.). (1962). Flight test manual (AGARD Volume 1, Chapter 8, 2nd ed.). Oxford, UK: Pergamon Press.

Eshelby, M E. (2000). Aircraft performance: Theory and practice. Boston: Elsevier.

European Aviation Safety Agency (EASA). (2007). Certification specifications for large aeroplanes CS-25 (Amendment 3, 19 September). Cologne, Germany: Author.

Farlow, S. J. (1993). Partial differential equations for scientists and engineers. New York: Dover.

Filippone, A. (2008). Comprehensive analysis of transport aircraft flight performance. Progress Aerospace Sciences, 44(3), 192-236. http://dx. doi.org/10.1016/j.paerosci.2007.10.005

Filippone, A. (2012). Advanced aircraft flight performance. New York: Cambridge University Press.

Germain, S. E. (2000). Airbus Industrie: Airbus A340 (Airliner Tech Series, Vol. 3). North Branch, MN: Specialty Press.

Gillespie, T. D. (1992). Fundamentals of vehicle dynamics. Warrendale, PA: Society of Automotive Engineers International (SAE).

Guo, J., Jian, X., \& Lin, G. (2014). Performance evaluation of an antilock braking system for electric vehicles with a fuzzy sliding mode controller. Energies, 7, 6459-6476. http://dx.doi.org/10.3390/ en7106459
Haney, P. (2003). The racing and high-performance tire: Using the tires to tune for grip and balance. Warrendale, PA: Society of Automotive Engineers International (SAE).

Holman, J. P. (1986). Heat transfer (6th ed.). New York: McGraw-Hill.

Jazar, R. N. (2008). Vehicle dynamics: Theory and applications. New York: Springer.

Jeppesen. (2007a). Airframes and systems (JAA ATPL Training Ed. 2 JAR Ref 021 01). Neu-Isenburg, Germany: Author.

Jeppesen. (2007b). Performance. (JAA ATPL Training, Edition 2, JA 310109-002, Book 9, JAR Ref. 032). Neu-Isenburg, Germany: Atlantic Flight Training, Ltd., Sanderson Training products, Jeppesen GmbH.

Kennedy, F. E. (2001). Frictional heating and contact temperatures. In B. Bhushan (Ed.), Modern Tribology Handbook (Vol. 1, 235-272), Boca Raton, FL: CRC Press.

Khapane, P. (2008). Simulation of landing gear dynamics and brake-gear interaction (Doctoral thesis, der Fakultaet fuer Maschinenbau der Technischen Universitaet at Carolo-Wilhelmina zu Braunschweig). Braunschweig, Germany: Author.

Limpert, R. (2011). Brake design and safety (3rd ed.). Warrendale, PA: Society of Automotive Engineers International (SAE).

Lombardo, D. (1993). Advanced aircraft systems. New York: McGrawHill.

Majumdar, P. (2005). Computational methods for heat and mass transfer. New York: Taylor \& Francis.

Medzorian, J. (1992). High speed aircraft tire dynamics/issues. SAE Technical Paper 921037. http://dx.doi.org/10.4271/921037

Milliken, W. F., \& Milliken, D. L. (1995). Race car vehicle dynamics. Warrendale, PA: Society of Automotive Engineers International (SAE).

Moir, I., \& Seabridge, A. (2008). Aircraft systems (3rd. ed.). New York: John Wiley \& Sons.

Myers, G. E. (1987). Analytical methods in conduction heat transfer. Schenectady, NY: Genium Publishing Corporation.

National Transportation Safety Board. (NTSB). (1990). Runway overruns following high speed rejected takeoffs (NTSB/SIR-90/02). Washington, DC: Author.

Neese, W. A. (1991). Aircraft hydraulic systems (3rd ed.). Malabar, FL: Krieger Publishing.

Nelson, R. C. (1998). Flight stability and automatic control (2nd ed.). New York: McGraw-Hill.

Olson, B. J., Shaw, S. W., \& Stépán, G. (2003). Nonlinear dynamics of vehicle traction. Vehicle System Dynamics, 40(6), 377-399. http://dx. doi.org/10.1076/vesd.40.6.377.17905

Özişik, M. N. (1985). Heat transfer: A basic approach. New York: McGraw-Hill.

Özişik, M. N. (1989). Boundary value problems of heat conduction. Mineola, NY: Dover.

Pacejka, H. B., \& Sharp, R. S. (1991). Shear force developments by pneumatic tires in steady-state conditions: A review of modeling aspects. Vehicle Systems Dynamics, 20(3-4), 121-175. http://dx.doi. org/10.1080/00423119108968983

Padilla, C. E. (1996). Optimizing jet transport efficiency: Performance, operations, and economics. New York: McGraw-Hill.

Patankar, S. V. (1980). Numerical heat transfer and fluid flow. Washington, DC: Hemisphere.

Press, W. H, Teulkolsky, S. A., Vetterling, W. T., \& Flannery, B. P. (1992). Numerical recipes in FORTRAN: The art of scientific computing (2nd ed.). Cambridge, UK: Cambridge University Press.

Reif, K. (Ed.). (2014). Brakes, brake control design and driver assistance systems: Function, regulation and components. Wiesbaden, Germany: Springer Vieweg.

Saelman, B. (1954). Airplane stopping distance. Journal of the Aeronautical Sciences, 21(11), 790-792. http://dx.doi.org/10.2514/8.3216

Sherwood, B. A., \& Bernard, W. H. (1984). Work and heat transfer in the presence of sliding friction. American Journal of Physics, 52(11), 1001-1007. http://dx.doi.org/10.1119/1.13775 
Spiegel, M. R., \& Liu, J. (1999). Mathematical handbook of formulas and tables (2nd ed.). New York: McGraw-Hill.

Swatton, P. J. (2008). Aircraft performance: Theory and practice for pilots (2nd ed.). Chichester, UK: John Wiley \& Sons.

Talati, F., \& Jalalifar, S. (2009). Analysis of heat conduction in a disk brake system. Heat Mass Transfer, 45, 1047-1059. http://dx.doi.org/ 10.1007/s00231-009-0476-y

Tannehill, J. C., Anderson, D. A., \& Pletcher, R. H. (1997). Computational fluid mechanics and heat transfer (2nd ed.). Philadelphia: Taylor \& Francis.

Tarter, J F. (1991). Electric brake simulation and modeling. SAE Technical Paper 911200. http://dx.doi.org/10.4271/911200

US Department of Transportation, Federal Aviation Administration (FAA). (1994). Takeoff safety training aid (AC 120-62). Washington, DC: Author.

US Department of Transportation, Federal Aviation Administration (FAA). (2000). Certification of transport airplane mechanical systems (Advisory Circular AC 25-22, March 14, 2000). Washington, DC: Author.

US Department of Transportation, Federal Aviation Administration (FAA). (2012a). Flight test guide for certification of transport category airplanes (Advisory Circular AC 25-7C, October 16, 2012). Washington, DC: Author.

US Department of Transportation, Federal Aviation Administration (FAA). (2012b). Aviation Maintenance Technician Handbook-Airframe (FAA H-8083-31, Vol. 2). Washington, DC: Author.

US Department of Transportation, Federal Aviation Administration (FAA). (2014). Part 25, Airworthiness standards: Transport category airplanes. Washington, DC: Author.

Wagenmakers, J. (1991). Aircraft performance engineering. New York: Prentice Hall.

Wild, T. W. (2008). Transport category aircraft systems (3rd ed.). Englewood, CO: Jeppesen.

Welty, J. R., Wicks, C. E., Wilson, R. E., \& Rorrer, G. (2001). Fundamentals of momentum, heat, and mass transfer (4th ed.). New York: John Wiley \& Sons.

Yager, T. J., Stubbs, S. M., \& Davis, P. A. (1990). Aircraft radial belted tire evaluation. SAE Technical Paper 901913. http://dx.doi.org/10. $4271 / 901913$

\section{Appendix A}

\section{Determination of Tire Friction and Longitudinal Slip}

The COF between a tire and a runway surface can be expressed with the following normalized speed-independent Burckhardt's tire model (Burckhardt, 1993):

$f(s)=C_{1} \cdot\left[1-\exp \left(-C_{2} \cdot s\right)\right]-C_{3} \cdot s \quad 0 \leq s \leq 1$

Guo, Jian, \& Lin (2014) and Olson and colleagues (2003) provide some values of the empirical Burckhardt's coefficients for various surfaces. Time derivative of tire longitudinal braking slip is:

$$
\dot{s}=\frac{R_{w}}{v^{2}} \cdot\left(\omega_{w} \dot{v}-\dot{\omega}_{w} v\right)
$$

We can tailor the non-dimensional experimental tireroad characteristics as a function of speed by finding proper-fitting coefficients. Conditions that must be fulfilled are:

$f(0)=0 \quad f(1)=f_{s} \quad f\left(s^{*}\right)=\left.1 \quad \frac{d f(s)}{d s}\right|_{s=s^{*}}=0$

If at particular speed $\mathrm{s}^{*}=0.20$, for our particular tire on a dry porous asphalt surface, at which the dimensionless slip function reaches the maximum (equal to one), then the system of two nonlinear equations can be solved using, for example, the Newton-Raphson (N-R) method. The coefficient $C_{3}$ can be expressed in terms of the other two coefficients, which reduces the order of the nonlinear system. The only other free coefficient we need to set is for the sliding friction (tire locked and slip is equal to one). We are using $f(1)=f_{s}=0.85$, which is in good agreement with many experimental results. The graphical result of the computation is presented in Figure A1.

The unknown coefficients are now: $C_{1}=1.0466, C_{2}=$ 24.3296, and $C_{3}=0.19619$. The anti-skid system can now be optimized to operate in the slip region: $0.10 \leq s \leq 0.30$. Other semi-empirical tire models could be used, such as Pacejka's magic formula (Pacejka \& Sharp, 1991), the LuGre tire model (Alroqi \& Wang, 2015; Canudas-de-Wit et al., 2003; Olson et al., 2003), etc.

The tire friction model can be extended now to include speed dependence (Burckhardt, 1993):

$$
\begin{aligned}
\mu(s, v)= & \left\{C_{1} \cdot\left[1-\exp \left(-C_{2} \cdot s\right)\right]-C_{3} \cdot s\right\} \\
& \cdot \exp \left(-C_{4} \cdot v\right) \quad 0 \leq s \leq 1
\end{aligned}
$$

A graphical result of computations for arbitrary tire and dry asphalt surface is shown in Figure A2, for which $C_{4}=$ 0.0075 was used (note: $1 \mathrm{~m} / \mathrm{s} \approx 1.94$ knots). Burkhardt's tire model is reasonably accurate for our needs. Since $e^{-k x} \approx 1-k x$, we could also use linear change COF with speed (Daidzic \& Shrestha, 2008):

$$
\mu_{p}(v)=\mu_{0} \cdot(1-K \cdot v) \quad \mu(s, v)=\mu_{p}(v) \cdot f(s)
$$




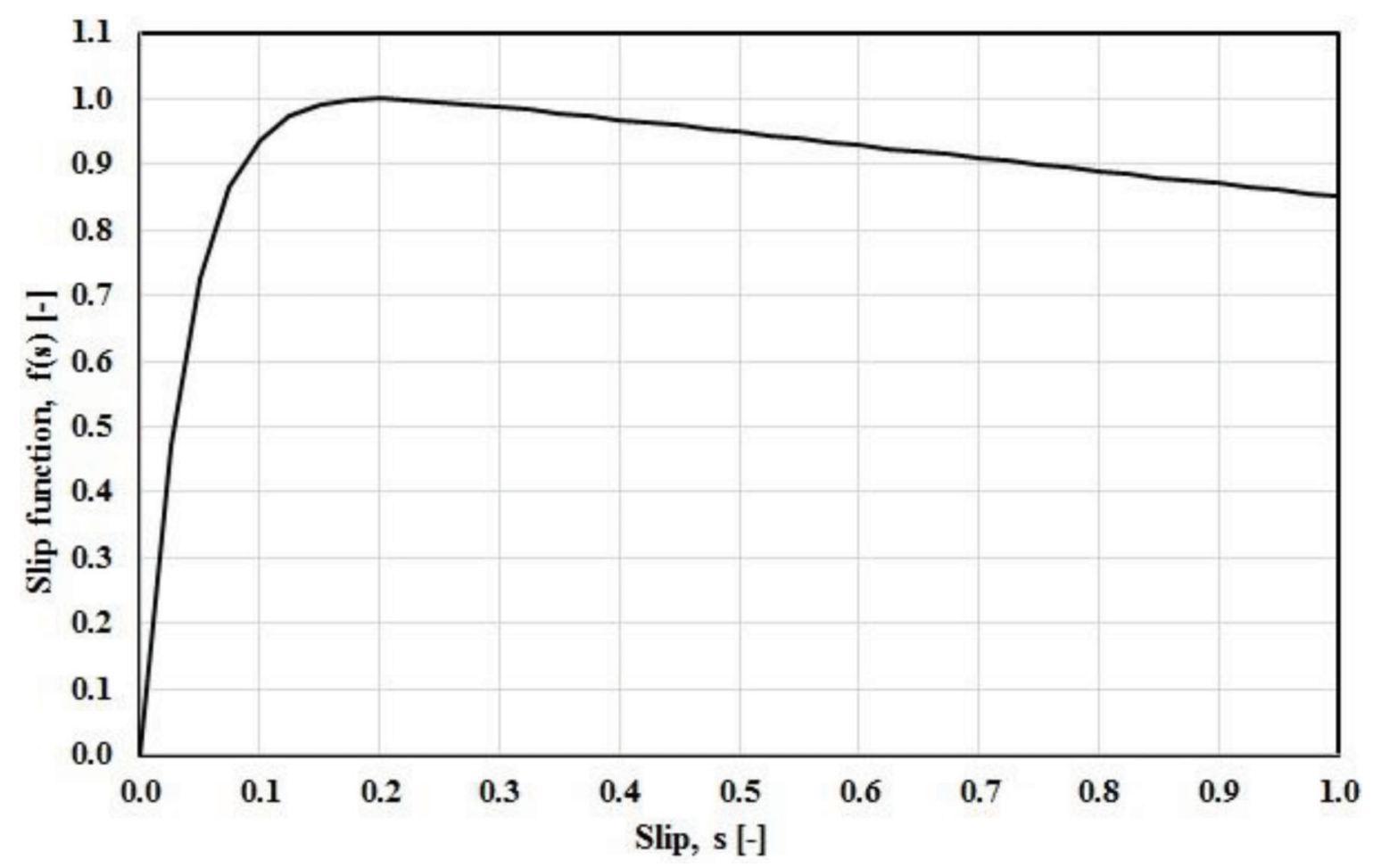

Figure A1. The dimensionless slip function for an arbitrary tire.

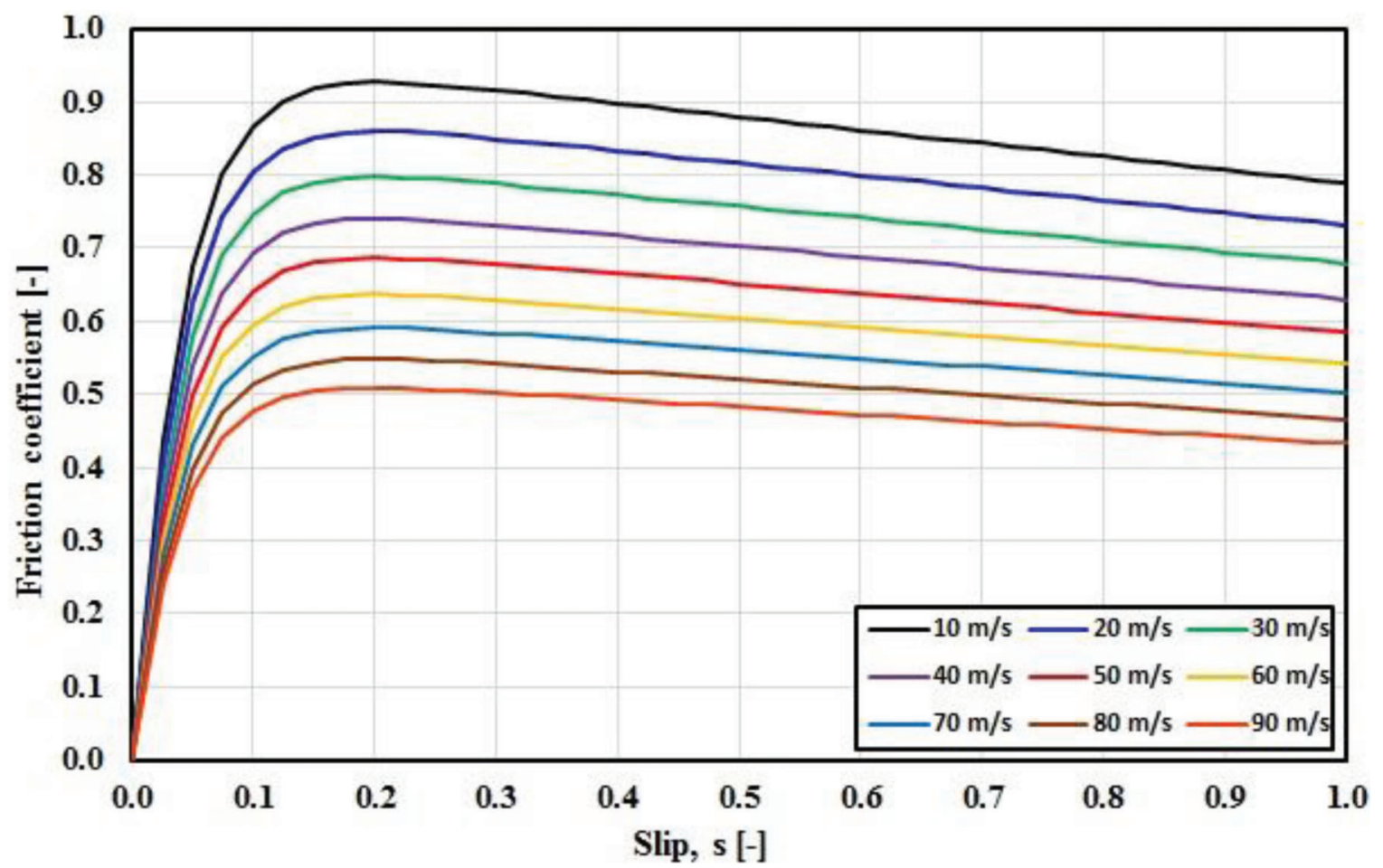

Figure A2. Friction coefficient for dry smooth asphalt runway as a function of tire slip and speed (Burkhardt's model). 


\section{Appendix B}

\section{Calculation of basic braking parameters}

The theory of contact (friction) forces is very complex and is commonly treated in tribology-the science of lubrication, friction, and wear. Frictional forces are phenomenological and described using constitutive laws. Several theories/hypotheses of Coulomb friction exist and for more details on irreversible thermodynamics of friction forces and heat generation, consult Amiri and Khonsari (2010), Kennedy (2001), and Sherwood and Bernard (1984).

Modern T-category airplanes exclusively use highperformance anti-skid controlled disc brakes. The anti-skid valve modulated hydraulic pressure acts on pistons in the pressure plate, which together with the end plate produces clamping force, squeezing rotors and stators together. Clamping force produces friction force and the braking torque, which slows the wheel/tire angular speed and dissipates aircraft motion energy. An illustration of a simple single disc-wheel-tire-axle assembly and a schematic of dynamic braking model with all dominant forces and moments of force is shown in Figure B1.

The brake factor (BF) is defined as the ratio of the friction and clamping force generating tangential friction force $F_{b}$ on both sides of the disc/rotor (Breuer \& Bill, 2008; Gillespie, 1992; Limpert, 2011):

$$
B F=C^{*}=\frac{2 F_{b}}{F_{C N}}=2 \cdot \mu_{b}
$$

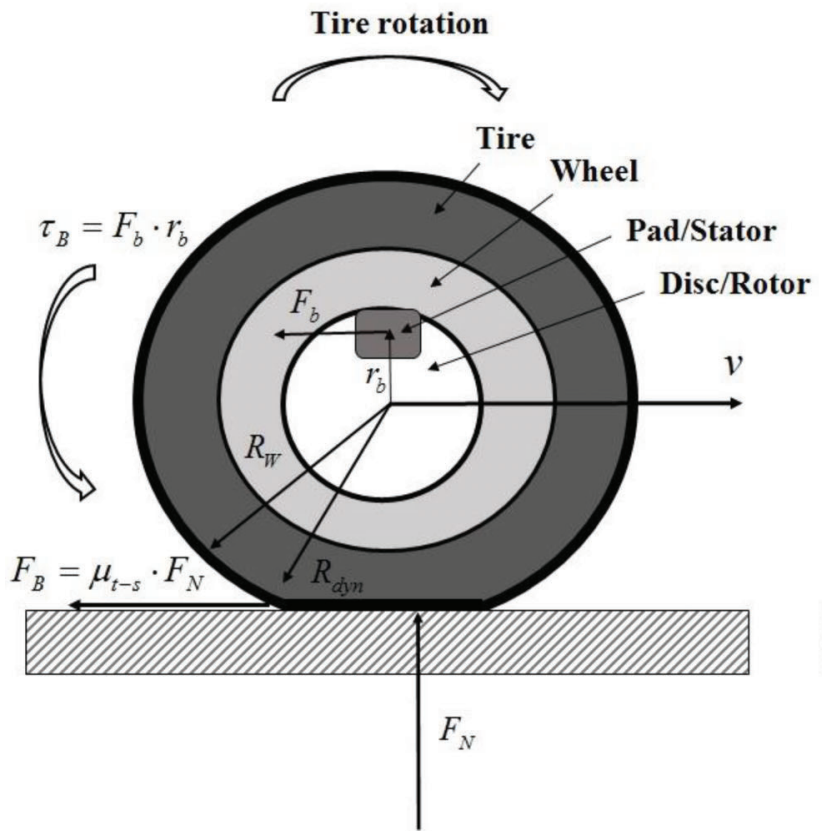

Depending on the brake lining material used, the $\mathrm{COF}$ $\left(\mu_{b}\right)$ is typically in the range of 0.35 to 0.5 , resulting in $\mathrm{BF}$ of 0.7 to 1.0 (Breuer \& Bill, 2008). Time-dependent clamping force $F_{C N}$ is a function of brake-piston(s) (BP) total cross-sectional area $\left(A_{B P}\right)$ and the instantaneous hydraulic pressure $p_{H}$ :

$$
F_{C N}(t)=p_{H}(t) \cdot A_{B P}
$$

The braking torque produced on a single disc is thus:

$$
\tau_{B}(t)=2 F_{b} \cdot r_{b}=2 \cdot \mu_{b} \cdot r_{b} \cdot F_{C N} \leq \tau_{B, \max }
$$

Here, $r_{b}$ is an effective (average) friction radius over which the clamped rotor-stator braking frictional force(s) creates braking torque on the wheel. This breaking torque is then transmitted to the surface through tire-pavement footprint. During service operations, the clamping force is rapidly modulated to prevent the braking torque from exceeding the maximum allowed, which would cause rapid wheel deceleration, locked condition, and sliding of the tire on the pavement (slip becomes 1.0 or $100 \%$ ). In locked condition, brakes are not absorbing any energy, which then is all being absorbed by tires causing their quick overheat and destruction. In reality, $\mu_{B P}$ is decreasing for higher sliding speeds. For example, assume an instant hydraulic brake pressure of 200 bar $(2,938 \mathrm{psi})$ and that the total brake piston cross-section area is $40 \mathrm{~cm}^{2}$ (e.g., 8 pistons of $5 \mathrm{~cm}^{2}$ ). The instantaneous clamping force is $80,000 \mathrm{~N}$ (80 kN) or about $17,985 \mathrm{lbf}$. Since both sides of the rotor are pressed with the respective stators and assuming $\mathrm{COF}$

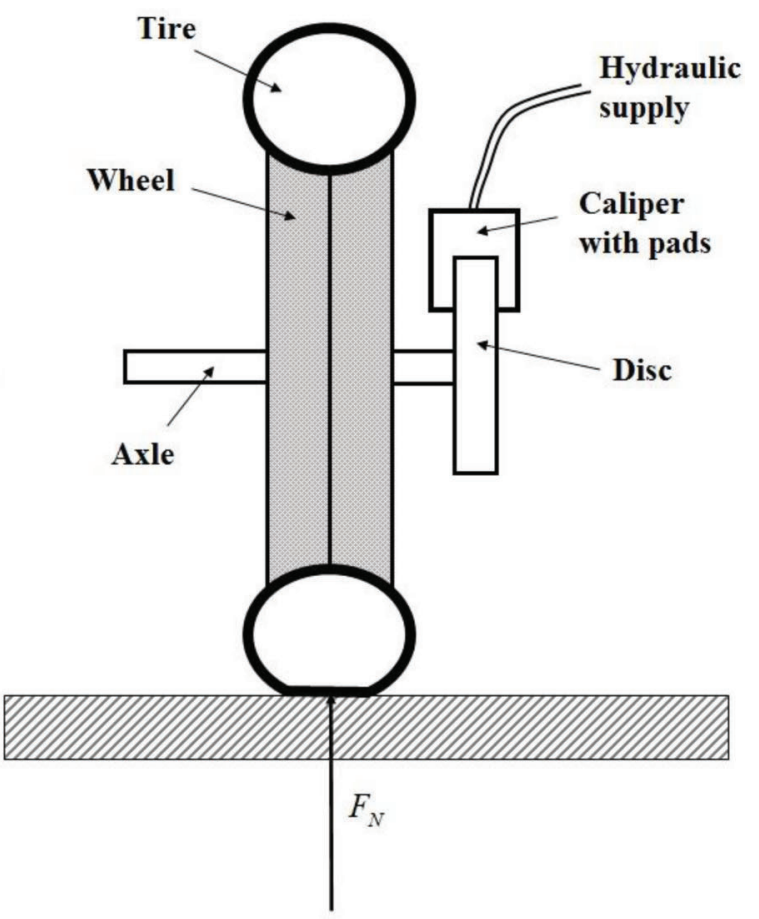

Figure B1. Illustration and functional schematic of a simple clockwise rotating single aircraft tire/wheel/disc caliper braking system. Not to scale. 


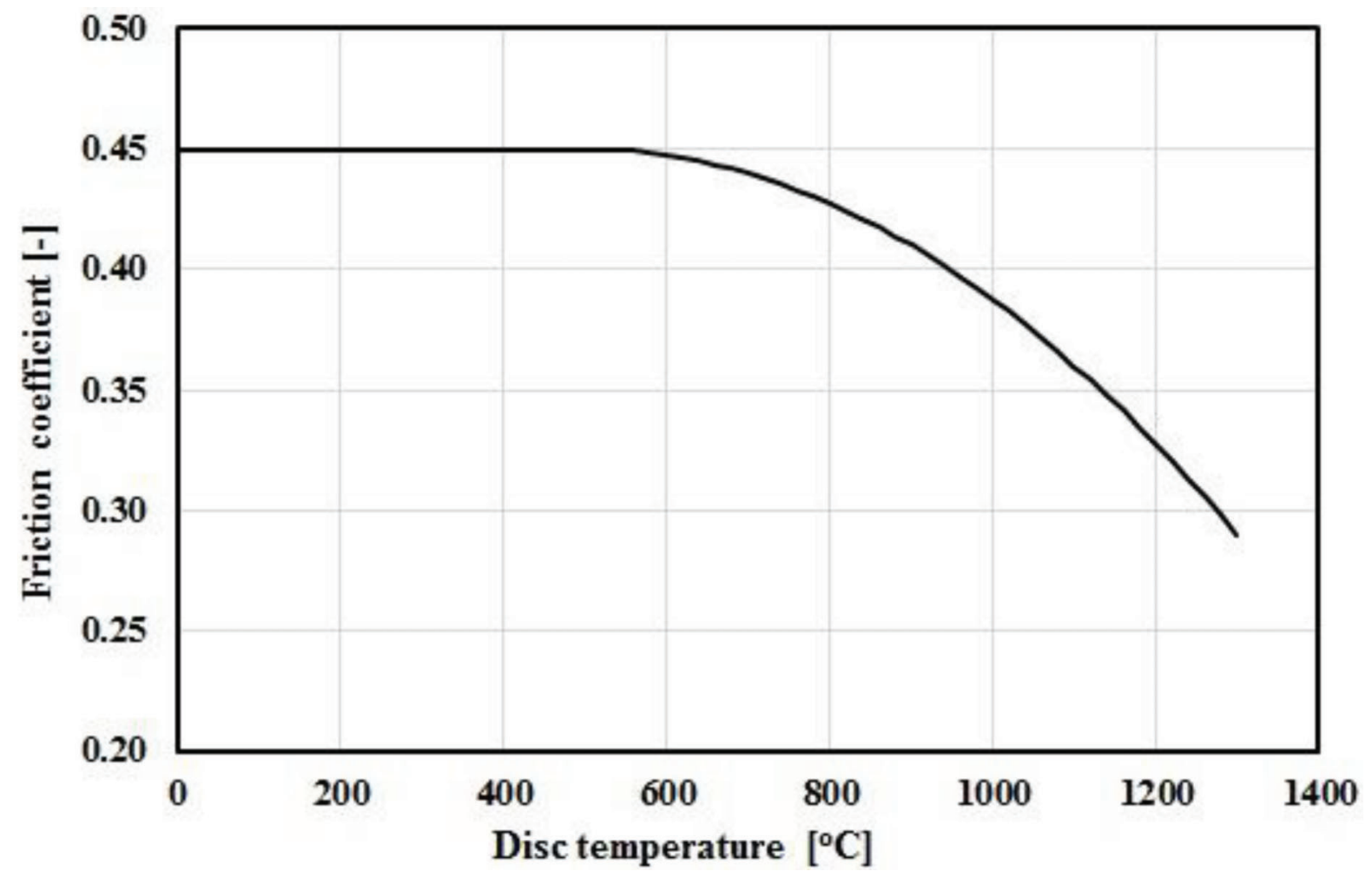

Figure B2. Temperature dependence of the disc-lining friction value for an imaginary brake system.

of about 0.4 , the total friction force on one rotor is $64 \mathrm{kN}$. Using the effective rotor/stator braking radius of $0.250 \mathrm{~m}$ on which the resultant friction force acts, the braking torque on one rotor becomes $16,000 \mathrm{Nm}$ or $11,801 \mathrm{ft}-\mathrm{lbf}$ (note: $1 \mathrm{lbf}=4.4482 \mathrm{~N}$ ). If there are five rotors (and six stators) on one brake assembly, the total braking torque generated on one wheel/tire is $80,000 \mathrm{Nm}(59,006 \mathrm{ft}-\mathrm{lbf})$. If the outside tire diameter is about 50 inches $(1.27 \mathrm{~m})$, the retarding force generated on a single tire is nominally $125.984 \mathrm{kN}(28,323 \mathrm{lbf})$. Since there are eight braking tires and assuming uniform efficiency, the total retarding force becomes about $1,008 \mathrm{kN}$ or $226,580 \mathrm{lbf}$. On a $410,000 \mathrm{lbf}$ airplane this braking force alone corresponds to $0.553 \mathrm{~g}$ deceleration $\left(17.78 \mathrm{ft} / \mathrm{s}^{2}\right.$ or $\left.5.42 \mathrm{~m} / \mathrm{s}^{2}\right)$ provided that runway surface and tire quality/design could support such frictional (adhesion and hysteresis) forces.

Brake fade is a serious problem that causes braking torques and forces to diminish due to excessive brake disc/ rotor temperatures. This is a very complicated phenomenon; for more details, consult Breuer and Bill (2008). Based on reported experimental results, we propose a semi-empirical expression for temperature-dependent sliding COF:

$$
\mu_{B P}(T)=\left\{\begin{array}{cc}
\mu_{B P 0} & T \leq T^{*} \\
\mu_{B P 0}-\xi \cdot\left(T-T^{*}\right)^{2} & T>T^{*}
\end{array}\right\}
$$

For example, if $\mu_{B P 0}=0.45$ for particular cool brakes, the critical temperature at which the brake fade starts is $T^{*}=500^{\circ} \mathrm{C}$, and the friction-lining material-dependent fitting coefficient of $\xi=2.50 \times 10^{-7}$, the disc-lining coefficient of friction at $T^{*}=1,140^{\circ} \mathrm{C}$ becomes $\mu_{B P}=0.3476$, resulting in $22.76 \%$ brake degradation (fade). The change of the rotor-stator/lining COF with the temperature $\mu_{B P}(T)$ is shown in Figure B2 for an imaginary SS brake design as used here. This brake fade analysis does not include the possibility of the brake fluid evaporating/boiling, which may have catastrophic consequences and results in a total loss of braking performance. Airplane stopping distance calculations already include moderate brake fade due to increasing temperature of frictional material. But any additional overheating of worn out brakes may cause significantly longer stopping distances. Brake fade curves can be obtained by measurements using different friction lining materials.

\section{Appendix C}

\section{Brake heat transfer model with convective and radiation cooling}

We are starting with a general parabolic Fourier heatconduction equation with internal heat generation in a 
cylindrical coordinate system $(r, \theta, z)$. All physical properties of friction materials are assumed constant, resulting in (Carslaw \& Jaeger, 1959; Farlow, 1993; Holman, 1986; Myers, 1987; Özişik, 1985, 1989; Welty et al., 2001):

$$
\begin{gathered}
\frac{\partial T}{\partial t}=a \cdot\left(\frac{\partial^{2} T}{\partial r^{2}}+\frac{1}{r} \frac{\partial T}{\partial r}+\frac{1}{r^{2}} \frac{\partial^{2} T}{\partial \theta^{2}}+\frac{\partial^{2} T}{\partial z^{2}}\right)+\frac{\dot{q}(r, \theta, z)}{\rho \cdot c_{p}} \\
a=\frac{\lambda}{\rho \cdot c_{p}}
\end{gathered}
$$

Due to the problem symmetry, the azimuthal dependence can be neglected. When thermal properties are temperature dependent and there are no internal sources of energy, we can write:

$$
\rho c_{p}(T) \frac{\partial T}{\partial t}=\frac{1}{r} \frac{\partial}{\partial r}\left[r \lambda(T) \frac{\partial T}{\partial r}\right]+\frac{\partial}{\partial z}\left[\lambda(T) \frac{\partial T}{\partial z}\right]
$$

IC: $\quad T(r, z, 0)=T_{0}$

As a matter of fact, for cast irons and steel alloys, thermal conductivity decreases while the specific heat capacity increases with temperature. Proper initial (IC) and boundary conditions (BC) need to be specified for PDE (Partial Differential Equations) problems (Initial Boundary Value Problem or IBVP). Many useful analytical solutions can be obtained using classical methods of solving heat-transfer parabolic PDEs, described in, for example, Carslaw and Jaeger (1959), Farlow (1993), Myers (1987), and Özişik (1989). Even simpler, a one-dimensional (1D) spatial temporal problem is obtained if radial distribution is neglected and only temperature distribution over disc thickness is considered (Limpert, 2011). The 1D problem is symmetric and easily solved (e.g., Farlow, 1993). The problem becomes nonlinear when radiation BCs are used. The cooling heat transfer on the disc surface is due to forced convection and radiation (especially at high temperatures) in cool enclosures with existing emissivity:

$\dot{Q}=\underbrace{\alpha \cdot A \cdot\left(T-T_{\infty}\right)}_{\text {convection }}+\underbrace{\varepsilon \cdot A \cdot \sigma \cdot\left(T^{4}-T_{\infty}^{4}\right)}_{\text {radiation }} \quad 0 \leq \varepsilon \leq 1$

Here, $\sigma$ is the Stefan-Boltzmann blackbody-radiation constant (Holman, 1986; Özişik, 1985). The only accurate way to solve the problem with complicated brake geometry and convective-radiation $\mathrm{BCs}$ is to use numerical methods, i.e., finite-differences, finite-volume, finite-element, etc. (e.g., Majumdar, 2005; Patankar, 1980; Press, Teulkolsky, Vetterling, \& Flannery, 1992; Tannehill, Anderson, \& Pletcher, 1997). For the cases where Biot number is small enough $(B i<0.1)$, a simple lumped-parameter analysis may be sufficient for basic transient analysis (Holman, 1986). If we take stainless steel disk with the coefficient of thermal conductivity of $\lambda=50 \mathrm{~W} / \mathrm{mK}$, and the convective (forced) heat-transfer coefficient of $\alpha=100 \mathrm{~W} / \mathrm{m}^{2} \mathrm{~K}$ (e.g., ventilated disc), then Biot number is 0.02 for a 2 -cm-thick disc.
Friction lining pads in road vehicles normally have much lower thermal conductivity (higher thermal resistance), generating significant internal temperature gradients. The mechanical braking energy enters the brake system at a point of friction contact between the pad and the disc. Most of the braking energy is converted into heat and transferred into disc (heat flux). At the same time, disc is cooled by forced convection and radiation. The thermal balance for the lumped-parameter system (disc) can be written as (Cauchy initial-value problem):

$$
M_{B} c_{B} \frac{d T}{d t}=\dot{E}_{B}-\dot{Q}_{c o m b} \quad I C: \quad T(0)=T_{0}
$$

The combined convective and radiation heat fluxes are $\dot{Q}_{\text {comb }}=\dot{Q}_{\text {conv }}+\dot{Q}_{\text {rad }}$. The mass of all brake discs and the surface area is:

$$
\begin{gathered}
M_{B}=n_{W} \cdot n_{D} \cdot\left(R_{D}^{2} \pi \cdot \delta_{D}\right) \cdot \rho_{D} \quad A_{B}=n_{W} \cdot n_{D} \cdot 2 \cdot R_{D}^{2} \cdot \pi \cdot\left(1+\frac{\delta_{D}}{R_{D}}\right) \\
\frac{V_{B}}{A_{B}}=\frac{\delta_{D} / 2}{\left(1+\delta_{D} / R_{D}\right)}
\end{gathered}
$$

Here, $n_{W}$ stands for the number of braked wheels, $n_{D}$ stands for the number of discs per wheel, $R_{D}$ stands for the disk radius, $\delta_{D}$ stands for disk thickness, and $\rho_{D}$ stands for disc material density. Combined convective and radiation heat transfer yield:

$$
\begin{aligned}
& \dot{Q}_{\text {comb }}=\alpha_{c o m b} \cdot A_{B} \cdot\left(T-T_{\infty}\right) \\
& \alpha_{c o m b}(T)=\alpha_{c o n v}+\varepsilon \cdot \sigma \cdot\left(T^{2}+T_{\infty}^{2}\right) \cdot\left(T+T_{\infty}\right)
\end{aligned}
$$

In this form the combined heat transfer coefficient is temperature dependent. Radiation heat transfer really becomes significant at high temperatures. The emissivity of grey cast iron is about 0.55 (Limpert, 2011). The Nusselt-number coefficient of convective heat transfer on a flat plate is (Holman, 1986; Özişik, 1985; Welty et al., 2001):

$$
N u=0.036 \cdot \operatorname{Pr}^{0.43}\left(\operatorname{Re}^{0.8}-9,200\right)
$$

Important non-dimensional numbers, such as Prandtl, Reynolds, and Nusselt, are defined respectively (Holman, 1986; Özişik, 1985; Welty et al., 2001) as:

$\operatorname{Pr}=\frac{v}{a}=\frac{c_{p} \mu}{\lambda} \quad R e=\frac{v \cdot \rho \cdot D}{\mu} \quad N u=\frac{\alpha_{c o n v} \cdot D}{\lambda}$

Here, $v$ is speed $[\mathrm{m} / \mathrm{s}], a$ is thermal diffusivity $\left[\mathrm{m}^{2} / \mathrm{s}\right]$, $\mu$ is dynamic viscosity $[\mathrm{Pa} \mathrm{s}], \rho$ is density $\left[\mathrm{kg} / \mathrm{m}^{3}\right]$, $\lambda$ is coefficient of thermal conductivity $[\mathrm{W} / \mathrm{m} \mathrm{K}], \alpha$ is coefficient of convective heat transfer $\left[\mathrm{W} / \mathrm{m}^{2} \mathrm{~K}\right], c_{p}$ is specific heat capacity $[\mathrm{J} / \mathrm{kg} \mathrm{K}]$, and $D$ is disc diameter [m]. Several laminar and turbulent convective heat transfer coefficients measured on circular disks are provided in Limpert (2011). For a solid, non-ventilated disc of diameter 
$D$, the convective heat transfer coefficient for laminar and turbulent flows, respectively, is:

$$
\begin{aligned}
& \alpha_{\text {conv }}=1.944 \times 10^{-4}\left(\frac{\lambda_{\text {air }}}{D}\right) R e^{0.55} \\
& \text { and } \alpha_{\text {conv }}=1.111 \times 10^{-4}\left(\frac{\lambda_{\text {air }}}{D}\right) R e^{0.8} \text { for } \operatorname{Re}>2.4 \times 10^{5}
\end{aligned}
$$

Heat transfer correlations for ventilated discs of a particular design are presented in Limpert (2011) and are not repeated here. Using Equation (C4), the average disc temperature becomes a function of time described with the linear non-homogeneous ODE with variable coefficients:

$$
\begin{gathered}
\frac{d T}{d t}+D \cdot T=G \cdot v_{A}(t) \cdot \frac{d v_{A}(t)}{d t}+H \cdot \phi \cdot v_{A}(t)+D \cdot T_{\infty} \\
I C: \quad T(0)=T_{0}
\end{gathered}
$$

where:

$$
\begin{gathered}
D=\frac{\alpha_{c o m b}(T) \cdot A}{M_{B} c_{B}} \quad G=\frac{M_{A} \cdot k}{M_{B} c_{B}} \quad H=\frac{M_{A} \cdot g}{M_{B} c_{B}} \\
T_{\infty}=\text { const. }
\end{gathered}
$$

The MBE criterion can be defined using the maximum allowable average temperature of a single disc, i.e., $T \leq T_{\max }$. Equation (C8) can be integrated numerically simultaneously with other dynamic equations of motion. Airplane acceleration can be modeled as (Daidzic, 2016b):

$$
a_{A}(t)=\frac{d v(t)}{d t}=c_{0}+c_{1} \cdot v+c_{2} \cdot v^{2}
$$

One simple analytic solution of Equation (C8) is obtained for constant acceleration and resulting linear speed decrease $\left(v_{A}(t)=v_{0}-a \cdot t\right)$, delivering thermal-balance ODE:

$$
\begin{aligned}
& \frac{d T}{d t}+D \cdot\left(T-T_{\infty}\right)=R-X \cdot t \\
& I C: \quad T(0)=T_{0}
\end{aligned}
$$

where $R=v_{0} \cdot(G \cdot a-H \cdot \phi)$ And $X=a \cdot(G \cdot a-H \cdot \phi)$.
The solution of this simple linear ODE is:

$$
\begin{aligned}
T(t)= & T_{\infty}+\left(T_{0}-T_{\infty}\right) \cdot e^{-D \cdot t}+\left(\frac{R}{D}+\frac{X}{D^{2}}\right) \\
& \cdot\left(1-e^{-D \cdot t}\right)-\frac{X}{D} \cdot t
\end{aligned}
$$

The theory of linear homogeneous and non-homogeneous constant-coefficients ODE is provided in, for example, Abell and Braselton (2010). The analytic solution of the lumped-parameter brake cooling heat-transfer in the presence of convection and radiation, where $T_{\infty}$ is constant enclosure (ambient) temperature and $T_{\max }$ is the initial (maximum) temperature, yields:

$$
\begin{aligned}
T(t) & =T_{\infty}+\left(T_{\max }-T_{\infty}\right) \cdot e^{-D \cdot t} \\
& =T_{\infty}+\left(T_{\max }-T_{\infty}\right) \cdot \exp (-B i \cdot F o)
\end{aligned}
$$

Dimensionless Biot and Fourier numbers are defined as (Holman, 1986):

$$
B i=\frac{\alpha}{\lambda} \cdot\left(\frac{V}{A}\right) \quad F o=\frac{a \cdot t}{(V / A)^{2}} \quad a=\frac{\lambda}{\rho \cdot c_{p}}
$$

Time to cool brakes to half of their initial (high) temperature can be estimated from:

$$
t_{1 / 2}^{*}=-\frac{1}{D} \cdot \ln \left(\frac{T_{0} / 2-T_{\infty}}{T_{0}-T_{\infty}}\right) \quad \frac{T_{0}}{2}>T_{\infty}
$$

Dr. Nihad E. Daidzic is a full professor of aviation, adjunct professor of mechanical engineering, and research graduate faculty member at Minnesota State University, Mankato. He is also president of AAR Aerospace Consulting, LLC. His PhD is in fluid mechanics and ScD is in mechanical engineering. He was formerly a staff scientist at the National Center for Microgravity Research and the National Center for Space Exploration and Research at NASA Glenn Research Center in Cleveland, $\mathrm{OH}$. He has also held various faculty appointments at Vanderbilt University, University of Kansas, and Kent State University. His current research interest is in theoretical, experimental, and computational fluid dynamics; micro- and nano-fluidics; aircraft stability, control, and performance; mechanics of flight, aircraft systems, and aerospace propulsion. Dr. Daidzic is ATP and and FAA-certified "Gold Seal" CFII/MEI/CFIG with flight experience in airplanes, helicopters, and gliders. 